OAK RIDGE

NATIONAL LABORATORY

MANAGED BY UT-BATTELLE

FOR THE DEPARTMENT OF ENERGY

ORNL/TM-2009/137

\title{
A REVIEW OF MATERIALS FOR GAS TURBINES FIRING SYNGAS FUELS
}

\section{MAY 2009}

T. B. Gibbons* and I. G. Wright

${ }^{*}$ Consultant

UT-BATTELLE 


\section{DOCUMENT AVAILABILITY}

Reports produced after January 1, 1996, are generally available free via the U.S. Department of Energy (DOE) Information Bridge.

Web site http://www.osti.gov/bridge

Reports produced before January 1, 1996, may be purchased by members of the public from the following source.

National Technical Information Service

5285 Port Royal Road

Springfield, VA 22161

Telephone 703-605-6000 (1-800-553-6847)

TDD 703-487-4639

Fax 703-605-6900

E-mail info@ntis.fedworld.gov

Web site http://www.ntis.gov/support/ordernowabout.htm

Reports are available to DOE employees, DOE contractors, Energy Technology Data Exchange (ETDE) representatives, and International Nuclear Information System (INIS)

representatives from the following source.

Office of Scientific and Technical Information

P.O. Box 62

Oak Ridge, TN 37831

Telephone 865-576-8401

Fax 865-576-5728

E-mail reports@adonis.osti.gov

Web site http://www.osti.gov/contact.html

This report was prepared as an account of work sponsored by an agency of the United States Government. Neither the United States Government nor any agency thereof, nor any of their employees, makes any warranty, express or implied, or assumes any legal liability or responsibility for the accuracy, completeness, or usefulness of any information, apparatus, product, or process disclosed, or represents that its use would not infringe privately owned rights. Reference herein to any specific commercial product, process, or service by trade name, trademark, manufacturer, or otherwise, does not necessarily constitute or imply its endorsement, recommendation, or favoring by the United States Government or any agency thereof. The views and opinions of authors expressed herein do not necessarily state or reflect those of the United States Government or any agency thereof. 


\section{Materials Science and Technology Division}

A Review of Materials for Gas Turbines Firing Syngas Fuels

T. B. Gibbons* and I. G. Wright

${ }^{*}$ Consultant

Date Published: March 2007

Prepared for the

U.S. Department of Energy

Fossil Energy Program

Prepared by

OAK RIDGE NATIONAL LABORATORY

Oak Ridge, Tennessee 37831-6285

Operated by

UT-Battelle, LLC

for the

U. S. DEPARTMENT OF ENERGY

Under contract DE-AC05-00OR22725 



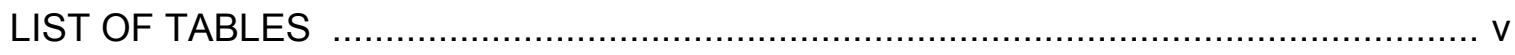

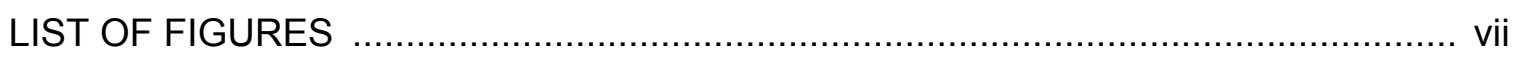

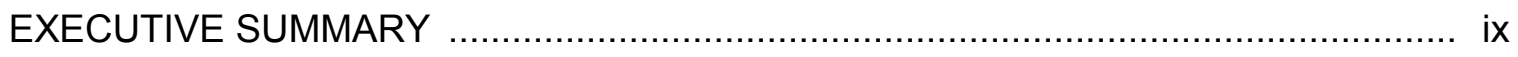

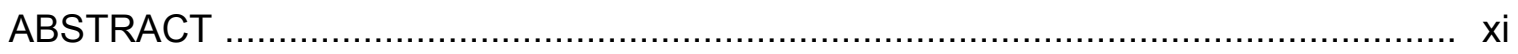

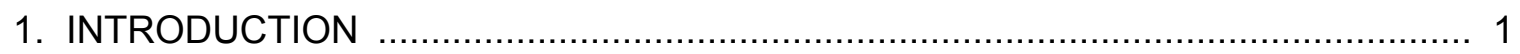

2. OVERVIEW OF ISSUES ARISING FROM BURNING DIFFERENT (GASEOUS)

FUELS GAS TURBINE ENGINES ……………...................................... 3

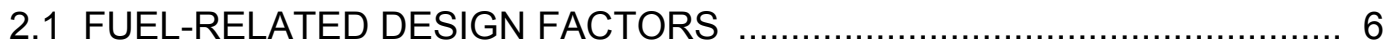

3. SOME CRITICAL ASPECTS OF CURRENT GAS TURBINE TECHNOLOGY ....... 13

4. THE CURRENT STATE OF THE ART IN MATERIALS

TECHNOLOGY FOR GAS TURBINES ……........................................ 17

4.1 ALLOYS FOR HP BLADES AND VANES ………............................ 17

4.2 COATINGS FOR HP BLADES AND VANES ………........................ 24

4.3 COMBUSTOR MATERIALS …………………........................ 28

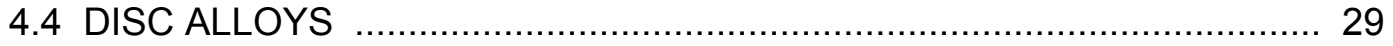

4.5 PREDICTION OF MATERIALS PROPERTIES BY COMPUTER

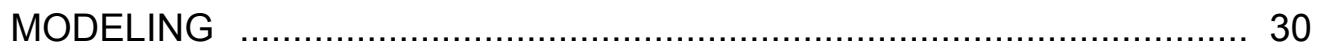

5. IMPLICATIONS FOR MATERIALS SELECTION IN GAS TURBINES

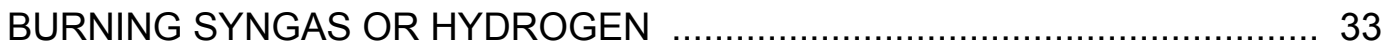

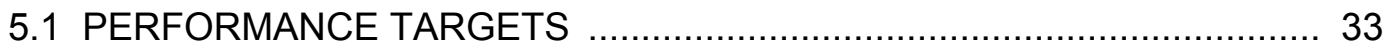

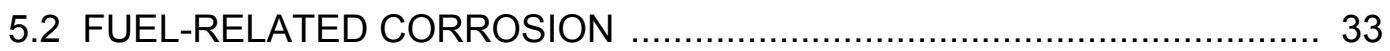

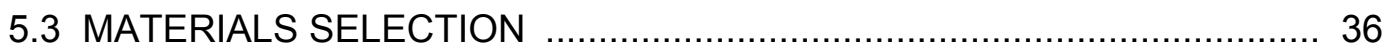

6. SUMMARY OF MATERIALS NEEDS …….................................................. 39

6.1 NEEDS RESULTING FROM THE PURSUIT OF HIGHER FIRING TEMPERATURES ……........................................................... 39

6.2 EVOLVING NEEDS FROM CONSIDERATION OF HYDROGEN AS GAS TURBINE FUEL ............................................................... 41

6.3 NEEDS RESULTING FROM CONCERNS ABOUT FUEL PURITY ......... 42

6.4 OVERALL SUMMARY OF MATERIALS NEEDS ……......................... 43

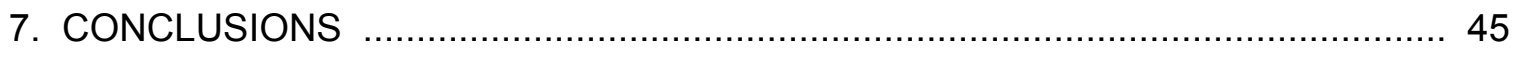

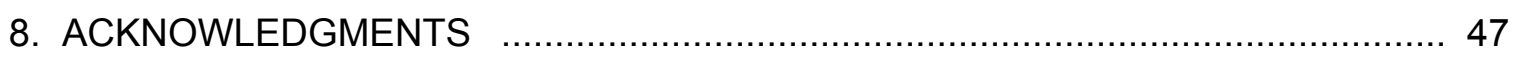

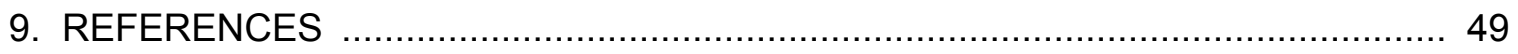





\section{LIST OF TABLES}

Table

Page

1 Some combustion properties of various fuels

2 Firing temperatures for typical large gas turbines produced in the USA

3 Nominal compositions of advanced Ni-based airfoil alloys (all are single crystal alloy except where indicated)

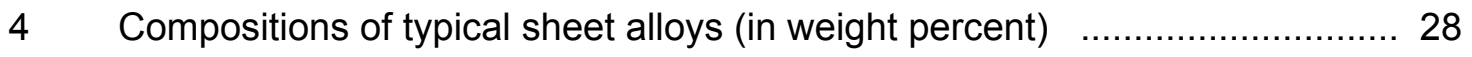

5 Compositions of typical Ni-base disc alloys (in weight percent) $\ldots \ldots \ldots \ldots \ldots \ldots . \ldots . \ldots . \ldots$

$6 \quad$ U.S. DOE performance targets for gas turbines burning coalderived gas

$7 \quad$ Ranking of overall materials needs 44 



\section{LIST OF FIGURES}

Figure

Page

1 Schematic illustration of a Siemens Model SGT5-8000H advanced gas turbine designed for combined cycle operation (from Siemens Power Generation

2 Schematic block diagram of a gas turbine indicating the overall gas flows

3 Schematic diagram of a gas turbine combustor

4 Schematic block diagram of the turbine section, suggesting blade cooling

5 Schematic block diagram of a gas turbine integrate with an air separation unit (ASU) for oxy-firing, suggesting the interconnectivity of the gas streams

6 Stress for rupture in $1,000 \mathrm{~h}$ as a function of temperature for single-crystal alloys

7 Creep rupture properties of single-crystal alloy CMSX-486

8 An example of a second stage vane quadruplet cast as a single-crystal

9 Comparison of trend in material temperature capability and turbine inlet temperature for aero-gas turbines

10 Micrograph and schematic diagram showing the various layers in a TBC system

11 Combustor liner manufactured from ceramic composite 



\section{EXECUTIVE SUMMARY}

As a result of the considerable development effort carried out in the 1990's, large gas turbines ( $250 \mathrm{~mW})$ for power generation are now operating reliably and with high availability ratings, in many parts of the world. However, since the price of natural gas has risen significantly, the gas turbine combined-cycle power system does not have the economic advantage over other generation technologies that applied a decade ago. Now, with the drive for zero emission power generation systems, other opportunities have opened up and, in particular, the coupling of a gas turbine combined-cycle system with coal gasification offers some attractive potential advantages in the context of reducing emissions. Furthermore, the use of coal-gasification technology will exploit the large U.S. reserves of coal, with the potential for easing the dependence on imported gas for power generation.

While there are many technical difficulties to be overcome in the successful integration of coal gasification and gas turbine combined-cycle (IGCC) technology, the emergence of large gas turbines as reliable, high-efficiency power generation systems is a major advantage. Thus, in developing IGCC technology, the gas turbine will represent a relatively mature technology at the heart of the generation system. There are, however, challenges to be faced in order to accommodate the physical and chemical differences of fuels other than natural gas. For example, the lower calorific value of syngas results in a substantial increase in the mass flows through the engine, compared with the combustion of natural gas and, while this will represent an increase in power output, there will be a need to modify the engine design to accommodate the increased gas flow. In addition, the higher hydrogen content of syngas (with its higher flame speed) may lead to difficulties in control of the combustion process. Thus, there are issues associated with different fuels that will have to be overcome in order to ensure reliable gas turbine operation.

As far as materials are concerned, the review has shown that the materials already available and/or currently under development for critical components in gas turbines burning natural gas will be applicable to units operating in IGCC systems. However since these materials have been developed for relatively clean environments, the higher levels of sulfur, water vapor, and possibly particulates likely to be encountered in syngas combustion will represent a potential limitation in terms of component durability. Thus it will be necessary to initiate development efforts to provide alloys with better corrosion resistance and coatings with enhanced corrosion and 
erosion resistance relative to the materials currently used in the cleaner natural gas combustion environments. Because the high-temperature properties of the current materials of choice in current high-performance gas turbines were obtained at the expense of inherent resistance to sulfidation or hot corrosion attack, this will be a significant task made all the more challenging if higher operating temperatures are required for greater generation efficiency. In order to provide data on impurity levels to guide the development effort, it will be important to have significantly better characterization of the composition of the gas produced from gasification and clean-up systems employed in IGCC. Finally, it will be necessary to demonstrate the operation of a complete advanced syngas- or hydrogen-fired turbine, or at least of the key enabling technologies, before the utility industry will accept such systems. Such a demonstration phase will be expensive, so that consideration should be given to a collaboration should be given to a collaborative effort, possibly a multi-national effort since the major gas turbine manufacturers are international companies.

In addition there will be a continuing need for better long-term data to characterize creep and fatigue performance of materials as a basis for improved design and reliable operation, as well as better definition of the actual conditions, especially temperature and temperature range, experienced by the key components in the hot gas path. In view of the difficulties in obtaining physical measurements of such needed parameters, increased use of computer modeling may be appropriate to predict materials behavior. Further, the more demanding combustion conditions with syngas may necessitate the evaluation of new materials (such as oxide dispersion-strengthened alloys or ceramics) for combustor applications. However, final decisions in this regard will depend on the precise chemistry of the combustion process, and the extent to which changes are required in engine design. Finally, it will be necessary to demonstrate the operation of a complete advanced syngas- or hydrogen-fired turbine, or at least of the key enabling technologies, before the utility industry will accept such systems. Such a demonstration phase will be expensive, so that consideration should be given to a collaborative effort, possibly a multi-national effort since the major gas turbine manufacturers are international companies.

The findings from this survey regarding materials needs for gas turbines burning coal-derived syngas are presented in summary form, along with an indication of the priority ranking for the individual requirements. 


\begin{abstract}
Following the extensive development work carried out in the 1990's, gas turbine combined-cycle (GTCC) systems burning natural gas represent a reliable and efficient power generation technology widely used in many parts of the world. A critical factor was that, in order to operate at the high turbine entry temperatures required for high efficiency operation, aero-engine technology, i.e., single-crystal blades, thermal barrier coatings, and sophisticated cooling techniques had to be rapidly scaled up and introduced into these large gas turbines. The problems with reliability that resulted have been largely overcome, so that the high-efficiency GTCC power generation system is now a mature technology, capable of achieving high levels of availability.

The high price of natural gas and concern about emission of greenhouse gases has focused attention on the desirability of replacing natural gas with gas derived from coal (syngas) in these gas turbine systems, since typical systems analyses indicate that IGCC plants have some potential to fulfil the requirement for a zero-emissions power generation system. In this review, the current status of materials for the critical hot gas path parts in large gas turbines is briefly considered in the context of the need to burn syngas. A critical factor is that the syngas is a low-Btu fuel, and the higher mass flow compared to natural gas will tend to increase the power output of the engine. However, modifications to the turbine and to the combustion system also will be necessary.

It will be shown that many of the materials used in current engines will also be applicable to units burning syngas but, since the combustion environment will contain a greater level of impurities (especially sulfur, water vapor, and particulates), the durability of some components may be prejudiced. Consequently, some effort will be needed to develop improved coatings to resist attack by sulfur-containing compounds, and also erosion.
\end{abstract}





\section{INTRODUCTION}

The major efforts worldwide in the 1990's devoted to improvements in materials and technology for gas turbines for electricity generation were driven by the demand for high-efficiency units burning natural gas. This demand resulted from a combination of factors that led to the gas turbine combined cycle (GTCC) system being the preferred method of power generation. These factors included:

- a reliable supply of relatively cheap natural gas with low sulfur content;

- widespread deregulation (actual and planned) of the power generation industry; and

- recognition of the need to reduce emissions of harmful greenhouse gases, and $\mathrm{CO}_{2}$ in particular.

The increased deregulation of the industry in the USA and Europe provided opportunities for independent power producers and owners of merchant plants to contribute to the increased demand for electricity. The advantages of GTCC plant in this regard were:

- low capital costs;

- construction time of about 24 months (compared with 36 months or more for a coal-fired plant);

- increased generation efficiencies compared with coal-fired plants; and

- the ability to meet stringent emissions targets, e.g. $\mathrm{NO}_{\mathrm{x}}<10 \mathrm{ppm}$.

Thus, in the USA in the late 1990's, gas and steam turbines for combined cycle operations represented over $60 \%$ of the annual orders for new power generating capacity. This rapid build-up reflected the small margin of excess generating capacity relative to demand resulting from the uncertainties associated with deregulation. ${ }^{1}$ One consequence of this surge in the demand for GTCC plants was that various R\&D projects were initiated with the overall aim of increasing the operating efficiency of this type of system to give a reduction in the cost of electricity. The most notable of these was the Advanced Turbine Systems (ATS) project in the USA, ${ }^{2}$ which was a $\$ 400$ million effort with well-defined targets for improved efficiency (60\%) and low emissions. Similarly, the Moonlight Project in Japan ${ }^{3}$ involved collaboration between the major turbine builders to develop an advanced gas turbine for power generation applications and, more recently, the High-Temperature Materials 21 Project $^{4}$ has provided an opportunity for further developments in Ni-base superalloys. In Europe, the COST 501 project ${ }^{5}$ was focused on development of improved materials and coatings to enable the 
production of components such as blades and vanes that would withstand the higher firing temperatures associated with high-efficiency gas turbines burning natural gas.

The result of this development effort was that by the mid 1990's, large gas turbines (around $250 \mathrm{MWe}$ ) firing natural gas were operating in combined cycle systems giving around $400 \mathrm{MWe}$ of power output with efficiency in excess of $55 \%$ in many cases, and with very low $\mathrm{NO}_{\mathrm{x}}$ and $\mathrm{SO}_{\mathrm{x}}$ emissions. Also, advanced concepts were being evaluated to give efficiencies of up to $60 \%$. With the rising cost of natural gas (the price generally tracks that of oil), attention has turned to the opportunities associated with the production of gas from coal. One consequence has been an interest in improving the technology of gas turbines burning low-Btu gas (syngas) with the aim of building on the advances made with the current generation of engines to improve generating efficiency with integrated gasification combined cycle (IGCC) plant. However, there are specific problems associated with the combustion of low-Btu gas, which will require additional development efforts both in specific aspects of turbine design, and in materials performance in order to provide cost-effective solutions.

In the following sections of this review, some critical aspects of gas turbine technology are outlined, the current status of materials for high-temperature components is briefly described, and the implications for the combustion of syngas and hydrogen are discussed. 


\section{OVERVIEW OF ISSUES ARISING FROM BURNING DIFFERENT (GASEOUS) FUELS GAS TURBINE ENGINES}

Modern gas turbine engines are complex machines in which materials are used to the limits of their capabilities in order to maximize the power and/or efficiency extracted from the fuel. Figure 1 shows a schematic view of an advanced land-based gas turbine, intended for use coupled to a heat-recovery steam generator and a steam turbine in combined cycle operation; the overall plant will generate $340 \mathrm{MWe}(50 \mathrm{~Hz})$ with an efficiency rating of $60 \%$ (higher heating value, $\mathrm{HHV}$ ).

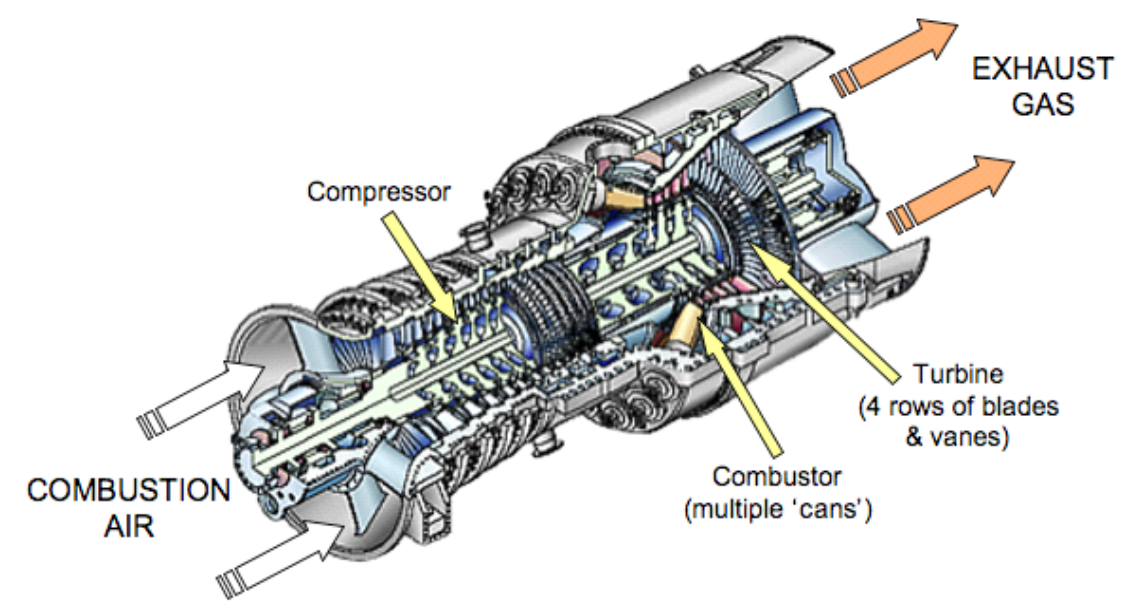

Fig. 1. Schematic illustration of a Siemens Model SGT5$8000 \mathrm{H}$ advanced gas turbine designed for combined cycle operation (from Siemens Power Generation). ${ }^{6}$

The current generation of land-based gas turbines was initially designed for operation on natural gas. Thus, the component dimensions and materials selection for these machines were determined by the power output required, the combustion characteristics of natural gas in air [as dictated by the stringent emissions limits (mostly $\mathrm{NO}_{\mathrm{x}}$ ) imposed], and the gas temperatures (as determined by the efficiency goals for the machine). Materials selection for the hot gas path components was based on the resulting gas flow rates and temperatures, as well as the stresses imposed in extracting work from the combustion gases. The degree of sophistication in terms of design and materials usage in modern land-based turbines is comparable to that in advanced aero engines, and techniques such as the use of complex airfoil profiles (based on 
computational fluid dynamics concepts) and active blade tip clearance control are employed to maximize efficiency. Cooling of some of these components is mandatory, since in places the temperature of the combustion gas exceeds the solidus temperature of the strongest available alloys.

Figure 2 is a simplified, schematic block diagram of a generic gas turbine, showing the major components, and indicating some of the gas flows. The bulk of the air exiting the compressor is directed into the combustion zone at locations and in amounts dictated by the requirements of the combustion process. The burner nozzle and combustor can and liner are designed specifically to control the flame characteristics of the fuel; cooling of the metallic combustor liner is achieved by flowing the incoming air over its outer surfaces, as well as through appropriately-sized and spaced holes, as indicated in Fig. 3. Air from the compressor also is used to cool some of the hot gas path turbine components; typically air is taken from locations in the compressor corresponding to the gas pressure at the particular location in the turbine where the coolant is needed. Figure 4 illustrates air cooling of the first two rows of blades and vanes in a four-stage turbine. Air from the compressor may be routed through the turbine discs into the blades, where cooling is accomplished by convection, direct impingement of air onto the inside surfaces of the airfoil walls, or released through holes in the trailing edge and blade tip. In more advanced designs, the air eventually is directed though carefully sized and shaped holes to provide a film of a cooling air over the external surfaces of areas of particular concern, such as the pressure (concave) surfaces.

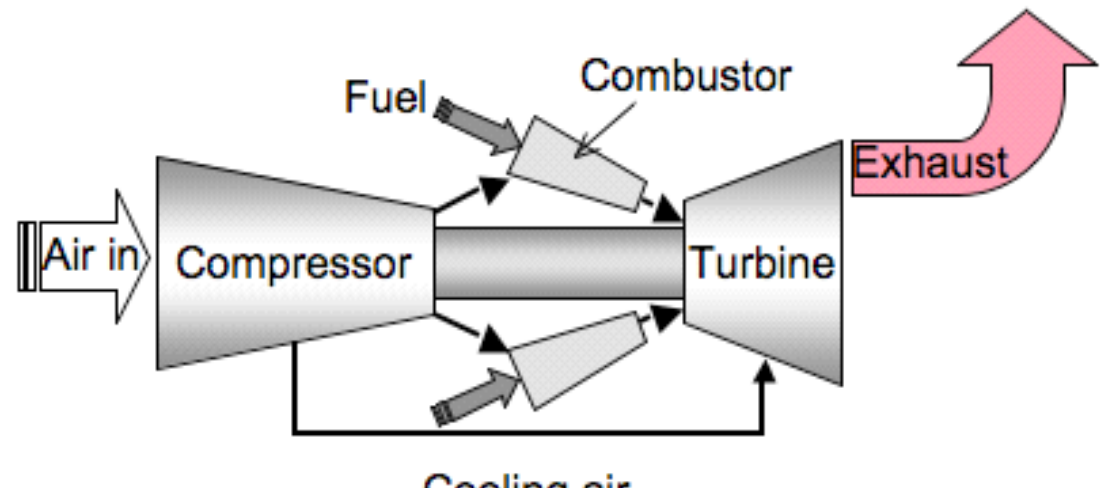

Fig. 2. Schematic block diagram of a gas turbine indicating the overall gas flows. 


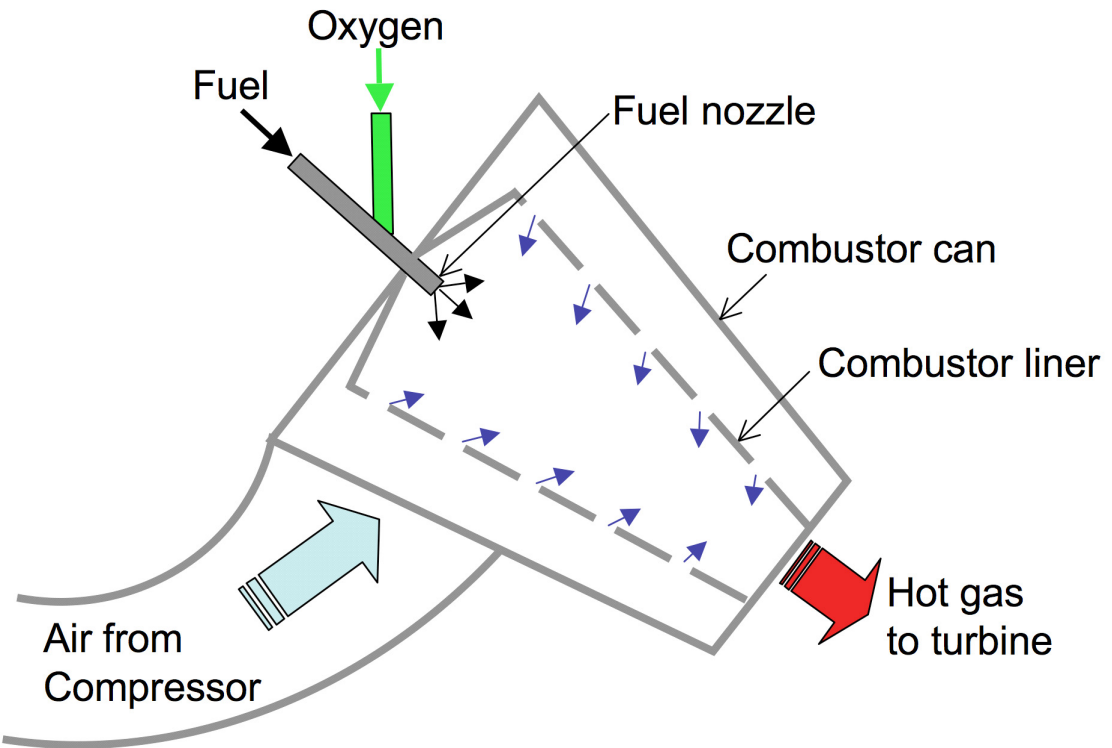

Fig. 3. Schematic diagram of a gas turbine combustor.

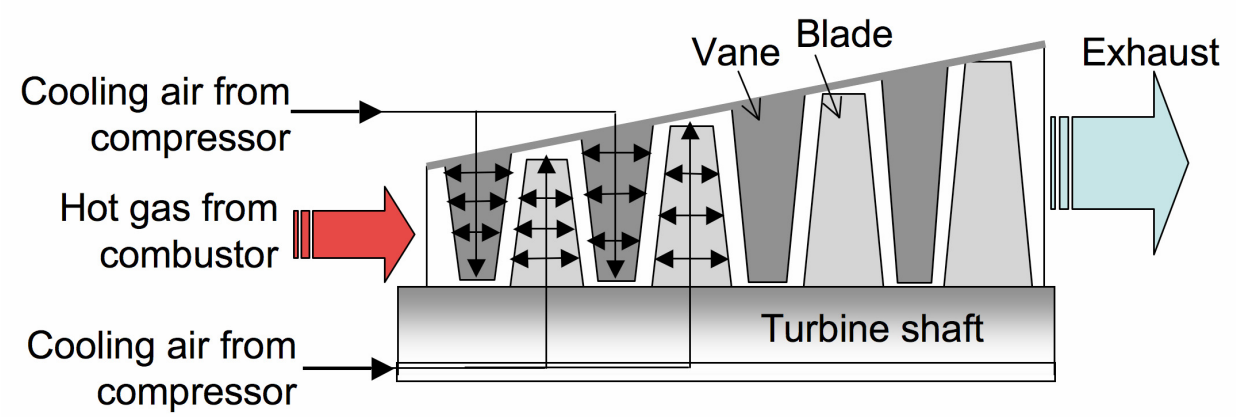

Fig. 4. Schematic block diagram of the turbine section, suggesting blade cooling. 


\subsection{FUEL-RELATED DESIGN FACTORS}

There are differences in composition between natural gas and syngas that result in differences in their combustion characteristics. The fuel gas generated by gasification of coal consists primarily of $\mathrm{H}_{2}$ and $\mathrm{CO}$, along with smaller amounts of $\mathrm{CH}_{4}$ and higher-order hydrocarbons, $\mathrm{CO}_{2}$, and $\mathrm{H}_{2} \mathrm{O}$; the level of $\mathrm{N}_{2}$ in syngas can vary from low to high, depending on whether the gasifier is oxygen- or air-blown. Also, there may be impurities in syngas not typically found in natural gas, which include sulfur, alkali species and solid particles at levels that depend on the original coal, the gasification process, and the characteristics of the gas clean-up processes employed. As a result, the properties of syngas that relate to its combustion characteristics can vary considerably. In simple terms, some key issues to be considered when using syngas or hydrogen rather than natural gas (taken here as essentially $\mathrm{CH}_{4}$ ) to fire a gas turbine are:

- Syngas (and hydrogen) have significantly higher laminar flame speeds than natural gas, giving rise to flame stability issues. Laminar flame speed $\left(s_{L}\right)$ is the rate at which a flame can propagate in a combustion mixture. If the flame speed is lower than the flow rate of the reactants, the flame may detach from the burner, whereas a flame speed higher than the flow rate of the reactants has the risk that the flame may flash back into the burner. Note that the value of $s_{\mathrm{L}}$ for methane (assumed here to be the same as natural gas) shown in Table 1 is only approximately $1 / 3$ that of a $50: 50 \mathrm{H}_{2}: \mathrm{CO}$ mixture (intended to simulate syngas), ${ }^{7}$ and that the flame speed of undiluted hydrogen is at least five times that of methane/natural gas. The flame speed of $\mathrm{H}_{2} / \mathrm{CO}$ mixtures decreases as the amount of dilution ( $\mathrm{CO}$ ) is increased, such that a value of $\mathrm{s}_{\mathrm{L}}$ equivalent that of natural gas can be achieved if the $\mathrm{H}_{2} / \mathrm{CO}$ ratio of 'syngas' is increased to 5:95 (Table 1). There is some effect of temperature on flame speed, and it was found that the measured and predicted values of $s_{L}$ tended to diverge at temperatures greater than $127^{\circ} \mathrm{C}^{7}$

- The levels of water vapor in the combustion gas from syngas (and hydrogen) are higher than in natural gas, and result in changes in the heat transfer properties of the flame, with implications for the ability to maintain adequate cooling of key components; high water vapor levels also may have detrimental effects on component durability. 
- The combustion of syngas probably will result in higher levels of unburned carbon than natural gas, which affects the luminosity flame hence heat transfer to the cooled components.

- The calorific value (CV) of syngas from an oxygen-blown gasifier typically is approximately $1 / 3$ that of natural gas (on a molar or volume basis), whereas that from an air-blown gasifier is lower $(\sim 1 / 10)$; also, the CV of hydrogen is approximately 0.3 times that of methane or natural gas on a volume basis (see Table 1). These large differences lead to differences in the relative gas flows in the turbine when compared on the basis of constant power, and have implications for combustor design, flame stability and increased heat transfer to the combustor can and airfoils.

Table 1. Some combustion properties of various fuels

\begin{tabular}{|c|c|c|c|c|c|}
\hline \multirow[t]{2}{*}{ Fuel } & \multicolumn{2}{|c|}{$\begin{array}{c}\text { Adiabatic flame T } \\
\left({ }^{\circ} \mathrm{C}\right)\end{array}$} & \multicolumn{2}{|c|}{$\begin{array}{c}\text { Calorific value } \\
\text { (HHV) }\end{array}$} & \multirow{2}{*}{$\begin{array}{l}\text { Maximum adiabatic } \\
\text { laminar flame speed } \\
\mathrm{cm} / \mathrm{s}\end{array}$} \\
\hline & Air & Oxygen & $\mathbf{k J} / \mathbf{k g}$ & $\mathrm{kJ} / \mathrm{m}^{3}$ & \\
\hline $\mathrm{CH}_{4}$ & $\begin{array}{l}1947^{8}- \\
2500^{9}\end{array}$ & $3327^{9}$ & $55,530^{9}$ & $39,820^{9}$ & $24^{7}-40^{8}$ \\
\hline Natural Gas & & & & $43,000^{9}$ & \\
\hline $\mathrm{H}_{2}$ & $\begin{array}{l}2110^{8}- \\
2657^{9}\end{array}$ & $3552^{9}$ & $\begin{array}{l}139,000^{10}- \\
141,790^{9}\end{array}$ & $13,000^{9}$ & $210-240^{7} ; 320^{8}$ \\
\hline $\mathrm{CO}$ & $2112^{8}$ & & & & $55^{8}$ \\
\hline $\begin{array}{l}\text { Syngas } \\
\text { (air-blown) }\end{array}$ & & & & $\begin{array}{l}4,500- \\
5,500^{11}\end{array}$ & \\
\hline $\begin{array}{l}\text { Syngas } \\
\left(\mathrm{O}_{2} \text {-blown }\right)\end{array}$ & & & & $\begin{array}{l}9,000- \\
13,000^{11}\end{array}$ & \\
\hline $\mathrm{H}_{2} / \mathrm{CO}(50-50)$ & & & & & $70-115^{7, a}$ \\
\hline $\mathrm{H}_{2} / \mathrm{co}(5: 95)$ & & & & & $20-40^{7, a}$ \\
\hline $\mathrm{C}_{3} \mathrm{H}_{8}$ & $2541^{9}$ & $3368^{9}$ & $\begin{array}{l}50,200^{10}- \\
50,350^{9}\end{array}$ & $101,000^{9}$ & \\
\hline $\mathrm{C}_{8} \mathrm{H}_{18}$ & $2550^{9}$ & $3481^{9}$ & & & \\
\hline Diesel oil & & & $\begin{array}{l}44,800^{10}- \\
45,500^{9}\end{array}$ & & \\
\hline Conv. gasoline & & & $\begin{array}{l}46,500^{10}- \\
47,300^{9}\end{array}$ & & \\
\hline
\end{tabular}

${ }^{a}$ Depending on equivalence ratio. 
- The corrosion potential of combusted syngas is expected to be greater than for natural gas, based on its increased water vapor content, and the likelihood of the presence of alkali and sulfur levels near the maximum typically allowed in turbine fuel specifications. ${ }^{12}$ The likely levels of condensable salts will depend on the details of the gas clean-up processing employed, but the possibility is allowed that they could approach the usual trigger points for initiation of deposition on some of the turbine stages. In fact, the higher fuel-to-air ratio in syngas combustion makes it likely that these trigger points will be reached with lower impurity levels in the fuel, with the result that the potential for hot corrosion in the turbine may be increased (depending on the range and amount of impurities present).

- Though significant emphasis in syngas clean-up is placed on particulate removal, until reliable data are available from sustained operation of IGCC plants, the possibility of erosive damage to the first stage vanes and blades should be acknowledged. Also, although stringent control of the combustion process will be practiced for emissions abatement, the formation of carbon-rich particles (and resulting erosion damage) also should not be overlooked.

- Control of the flue gas exit temperature may be more difficult than with natural gas, which may present problems for the downstream heat-recovery steam generator.

The differences in such properties among natural gas, syngas, and hydrogen highlight the need to evaluate the implications for design and operation of gas turbine combustion systems intended to operate on different fuels. Figure 5 shows the relative gas flows in a turbine (using the schematic layout from Fig. 2), and is intended to provide some indication of the interdependence among the air and fuel flows; in addition, the case of coupling the gas turbine with an air separation unit (ASU) to permit oxygenaugmentation of the combustion air is considered. Note that the gas turbine compressor is assumed to supply air not only for combustion (stream $A_{1}$ ), but also for cooling of hot section components $\left(A_{2}, A_{3}\right)$; compressor air also may be supplied to the gasifier (stream $A_{4}$ ). There is also the possibility that for oxy-firing, the air feed for the ASU would be provided by the turbine compressor (stream $A_{5}$ ). The flow of combustion air (and/or oxygen) and fuel ( $F)$ are related by the combustion characteristics required by the turbine power and emissions specifications. Where the fuel requires dilution to avoid explosive mixtures, or to control $\mathrm{NO}_{\mathrm{x}}$ formation, the gas flow in the combustor will include $\mathrm{N}_{2}$ or steam additions, which have been omitted from this discussion for the sake of simplicity. 


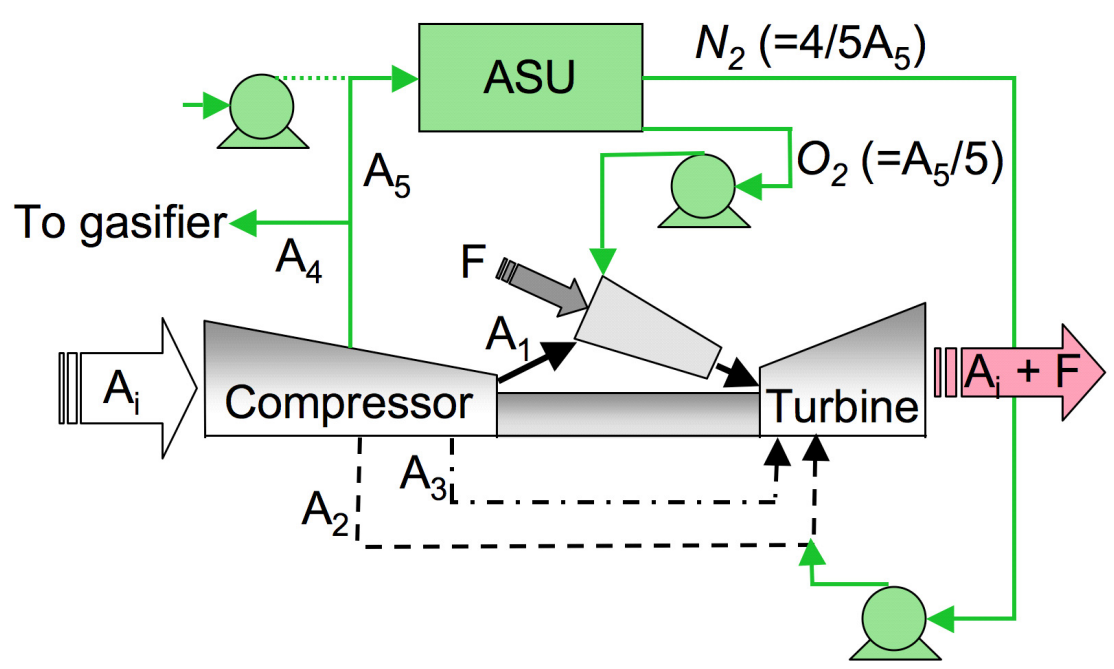

Fig. 5. Schematic block diagram of a gas turbine integrate with an air separation unit (ASU) for oxy-firing, suggesting the interconnectivity of the gas streams.

A further important issue is that the temperatures of hot gas path components (such as first stage vanes and blades) must be tightly controlled to prevent them from exceeding their strength capability limits. Thus, the cooling provided by streams $A_{2}$ and $\mathrm{A}_{3}$ is critically important, and must be matched to the heat transfer associated with the combustion of each fuel (or the combustion temperature must be decreased to allow the temperature of the critical vanes and blades to be maintained below some critical level). This is a problem when switching fuels, since for a given turbine design, the values of the flow rates of streams $A_{2}$ and $A_{3}$ are not readily variable. In terms of the turbine cycle, since the cooling air streams $A_{2}$ and $A_{3}$ do not contribute to the combustion process, they detract from the overall efficiency of the engine, and so should be minimized. Other sources of coolant have been considered, such as steam cooling by integration of the gas turbine with the steam circuit in a combined cycle ${ }^{13}$ and, for oxy-firing, the nitrogen from the ASU might be used for this purpose, thus possibly reducing the air flow in streams $A_{2}$ and $A_{3}$.

These simple considerations suggest that different compressor and turbine flows will be needed to allow the optimized use of different fuels, in order to accommodate the differences arising from, for example, variations in the $\mathrm{CV}$ of natural gas, syngas and hydrogen, and adjustments of other flows to provide adequate cooling. While quantification of the flow streams suggested in Fig. 5 for any fuel is not straightforward, the following simplified argument is presented as a means for obtaining a rough 
approximation of the magnitude of the changes expected in flow rates in key areas, due to combusting syngas or hydrogen in a gas turbine designed for natural gas.

The gas flow through the combustor is composed of the flows of combustion air $\left(A_{1}\right)$ and fuel $(F)$, and these two components are related by the molar proportions of the reacting species, and the air-to-fuel ratio (or overall stoichiometry, $\eta$ ). The continuation of natural gas $\left(\mathrm{CH}_{4}\right)$ is considered to involve:

$$
\mathrm{CH}_{4}+2 \mathrm{O}_{2}+\left(8 \mathrm{~N}_{2}\right)=\mathrm{CO}_{2}+2 \mathrm{H}_{2} \mathrm{O}+\left(8 \mathrm{~N}_{2}\right)
$$

On the basis on one mole of methane combusted, the molar (volume) flow through the combustor is $(1+1 \eta)$, and through the turbine $[3+(8 \eta+2 \eta-2)]+\left(A_{2}+A_{3}\right)$. For an air/fuel ratio of 20 , and the total cooling air flow extracted from the compressor is $0.05 \mathrm{~A}_{1}$, the molar flows through the combustor and turbine are 201 and 211 , respectively, so that the turbine flow rate is approximately $4 \%$ greater than that through the combustor.

For syngas from an oxygen-blown gasifier, assuming that the gas consists of 1 part $\mathrm{CH}_{4}+2$ parts $\mathrm{N}_{2}(\mathrm{CV}=1 / 3$ that of natural gas, and 1 mole of natural gas is represented by $\mathrm{CO}+3 \mathrm{H}_{2}$ ), the combustion process can be represented by:

$$
\mathrm{CO}+3 \mathrm{H}_{2}+2 \mathrm{O}_{2}+8 \mathrm{~N}_{2} \text { (air) }+\left(8 \mathrm{~N}_{2} \text { from gasifier }\right)=\mathrm{CO}_{2}+3 \mathrm{H}_{2} \mathrm{O}+10 \mathrm{~N}_{2}
$$

The combustor and turbine flows become $(12+10 \eta)$, and $\left[(12+8 \eta+2 \eta-2.5)+\left(A_{2}+A_{3}\right)\right]$, respectively, and for $\eta=20$ and $\left(A_{2}+A_{3}\right)=0.05 A_{1}$, the molar flows are 212 and 219.5 respectively, an increase for the combustor of $5 \%$ compared to natural gas, and $4 \%$ for the turbine.

For the stoichiometric combustion of hydrogen in oxygen (assuming that the CV of hydrogen $=1 / 3 \mathrm{CH}_{4}$, Table I):

$$
3 \mathrm{H}_{2}+3 / 2 \mathrm{O}_{2}=3 \mathrm{H}_{2} \mathrm{O}+6 \mathrm{~N}_{2} \text { (coolant) }
$$

The combustor and turbine molar flows for the nominally same turbine power would be 4.5 and $\left[3+\left(A_{2}+A_{3}\right)\right]$, respectively, (assuming that all of the turbine cooling could be accomplished by the nitrogen component of stream $A_{5}$, as suggested in Fig. 5). The combustor and turbine flows would be 4.5 and 9 , respectively. Compared to natural gas, these flows represent a significant mismatch in combustor and turbine sizes. 
Overall, it is suggested that a syngas-fueled machine would experience higher gas flows through the combustor and turbine than when burning natural gas, and that these would increase with decreasing CV of the syngas. In the case of a hydrogen-fired turbine, the gas molar flows through the combustor and turbine will be significantly decreased compared to firing with natural gas. It is clear from these simple arguments that there are significant implications for the design of the turbine that must be addressed especially for the combustor, from the desire to burn different fuels. Some accommodation of the mismatches in flow rates among the fuels can probably be made by the inclusion of variable guide vanes in the compressor or turbine first stages, or by changing the shape of the first-stage turbine vane to reduce the pressure drop resulting from increased flows. However, it is not obvious that the differences in combustion characteristics can be accommodated in a single combustor design that can maintain the desired emissions values of, for instance, $\mathrm{NO}_{\mathrm{x}}$. 



\section{SOME CRITICAL ASPECTS OF CURRENT GAS TURBINE TECHNOLOGY}

Prior to the rapid build-up in GTCC generating capacity, gas turbines for power generation had chiefly been used in simple-cycle operations for "peak lopping" applications. ${ }^{14}$ In this case, the rapid start-up capability of the gas turbine was a major advantage and, in view of the short operating time, there was no great requirement for high efficiency. Consequently, these engines used relatively low firing temperatures compared with the maximum capabilities of aero-engines, and were much less sophisticated in design, so that relatively low-strength alloys could be used for components such as blades and vanes, and cooling technology was generally not required. Some of the smaller engines were derivatives of existing aero-engines, which were derated for land-based application.

By comparison, the development of large (250 MWe) gas turbines operating as base-loaded units for power generation in GTCC systems required a new approach to materials and component design in order to cope with the higher firing temperatures consistent with the demand for high efficiency and low cost of electricity. Some typical firing temperatures in advanced land-based gas turbines from the major manufacturers are shown in Table 2, along with calculated efficiency values. ${ }^{15}$

Table 2. Firing temperatures for typical large gas turbines produced in the USA

\begin{tabular}{lccc}
\hline \multicolumn{1}{c}{ Engine } & $\begin{array}{c}\text { Rotor inlet } \\
\text { temperature } \\
\left({ }^{\circ} \mathbf{C}\right)\end{array}$ & $\begin{array}{c}\text { Power output } \\
\text { (MWe) }\end{array}$ & $\begin{array}{c}\text { Predicted efficinecy } \\
(\%)\end{array}$ \\
\hline Westinghouse 501G & 1426 & 240 & 58 \\
Siemens V84/3a & 1310 & 170 & 57 \\
Alstom GT24/26 & 1240 & $188 / 281$ & 57 \\
General Electric 7FA & 1290 & 150 & 55
\end{tabular}

As a result, technology that previously had been used only in aero-engines was rapidly adopted for GTCC application. This included the use of advanced casting processes for producing blades and vanes containing complex cooling passages associated with sophisticated cooling techniques, and the introduction of improved coating technology (including thermal barriers) to give effective protection at the highest temperatures. These requirements represented a considerable technical challenge to the manufacturers and component suppliers and, not surprisingly, there were difficulties 
(particularly with the earlier engines) so that reliability, and hence availability, was poor for some engine designs. However, with modifications and detailed improvement in design, these difficulties were gradually overcome, so that (it is claimed) current variants of these engines perform well, with high levels of availability.

Consequently, the current generation of land-based gas turbine engines has reached a certain level of technological maturity, and can be characterized by the following features:

- extensive use of thermal barrier coatings (TBCs) or ceramic tiles in the combustor lining;

- single-crystal (SC) blades and vanes for the first stage of the high-pressure turbine, operating with metal surface temperatures of $950^{\circ} \mathrm{C}$ or more, and with complex patterns of cooling holes to maintain desired cooling levels while minimizing the amount of cooling air required;

- highly oxidation-resistant metallic coatings (usually NiCrAl-base) on blades, vanes and combustor surfaces;

- extensive application of TBCs on the first stage blades and vanes, with a $\Delta T$ capability of the order of $150^{\circ} \mathrm{C}$ to enable desired cooling levels to be achieved;

- directionally-solidified (DS) blades and vanes for the remaining rows in the high-pressure turbine, operating at somewhat lower temperatures; and

- Ni-base alloys (rather than ferritic steels) in some cases, for high-pressure turbine discs.

Despite the considerable experience with these advanced materials in aero-engine applications, transfer of the technology to the much larger, land-based turbines was not a straightforward matter, and involved a substantial development effort by the manufacturers and component suppliers. Difficulties arose in the following areas:

- production of SC blade castings, where difficulties in maintaining control of the solidification process as the size of the components increased resulted in defects such as low-angle boundaries and 'stray' grains;

- misalignment of the columnar grains in DS components because of the increase in component size;

- inadequate coating and processing methods for both oxidation-resistance and thermal barriers; and

- $\quad$ processing of large disc forgings of Ni-base alloys.

Solutions were developed for most of these problem areas, by both modification to alloy and coating compositions, and by improvements in processing methods, for 
example, casting and coating deposition techniques. As far as improvements in processing were concerned, computer-modeling methods for casting and forging were instrumental in defining optimum conditions. An important outcome of these improvements was that yields, particularly of SC castings, were greatly increased, contributing to decreased costs. ${ }^{2}$

Thus, it is apparent that the introduction of advanced gas turbine technology to the power generation business was a high-risk endeavor, with severe financial consequences resulting from the effort required to overcome problems that emerged during commercial operation of some of the earlier engines. Now, however, these machines appear to be operating reliably, and the technology has reached a level of maturity that can provide a basis for the development of high-efficiency engines suitable for application in IGCC systems. It is acknowledged that modifications will be required to achieve the desired efficiencies and emissions reduction when fired by syngas, and some changes in design will be necessary to accommodate differences in combustion characteristics and mass flow. In this regard, modifications in combustor design will probably represent one of the more challenging areas for improvements in materials selection and application. 



\section{THE CURRENT STATE OF THE ART IN MATERIALS TECHNOLOGY FOR GAS TURBINES}

\subsection{ALLOYS FOR HP BLADES AND VANES}

For some years now these components, which are subjected to the highest temperatures and, in the case of blades, the highest stresses in the turbine, have been manufactured from SC castings of high-strength, Ni-based superalloys. The concept of directional solidification (DS) began to be developed in the 1960's to improve ductility and also low-cycle fatigue performance by eliminating the transverse grain boundaries, which usually were associated with fracture. In the early days, the process was limited to small components in military engines, but the technology has developed to the stage where the relatively large blades and vanes used in gas turbines for electric power generation in either simple- or combined-cycle mode are routinely produced as single crystals. The high rotor-inlet temperatures (RITs) necessary to obtain the high efficiencies required to give relatively low generation costs result in surface temperatures for hot gas path components that make castings in SC superalloys essential for the blades and vanes in the first stage (and possibly second stage) of the turbine. The advantages of SC castings have been well documented ${ }^{16}$ and include:

- improved creep and stress rupture properties;

- enhanced fatigue performance (for both low-cycle fatigue and thermo-mechanical fatigue);

- good oxidation resistance (particularly for the $2^{\text {nd }}$ generation SC alloys); and

- increased reliability of coatings.

In parallel with the development of casting technology, there has been a substantial effort aimed at developing alloy compositions specifically tailored for casting as SCs. The emphasis has been to optimize the alloy composition in the absence of grain boundary-strengthening additions (such as $\mathrm{C}, \mathrm{B}$ and $\mathrm{Zr}$ ). One consequence of omitting these additions has been to raise the incipient melting point, thereby allowing heat treatments to achieve full solutioning of the $\gamma^{\prime}$ strengthening phase, and so increase the volume fraction that can be precipitated on subsequent heat treatment, hence maximizing strength at high temperature. Further improvements were obtained by the addition of rhenium, which had a major effect in increasing the strength of the alloy, while necessitating a reduction in the content of chromium. The resulting series of advanced superalloys for SC components has been characterized as $1^{\text {st }}-, 2^{\text {nd }}-$, or $3^{\text {rd }}-$ 
generation alloys, largely on the basis of the rhenium content. Recently, further improvements in creep strength have been claimed as a result of additions of iridium and ruthenium together with rhenium; while these alloys tentatively have been characterized as $4^{\text {th }}$ - and $5^{\text {th }}$-generation, respectively there is little sign that they will be used commercially. ${ }^{17}$ The compositions of some typical alloys representative of each development phase (or generation) are given in Table 3.

Only alloys classed as $2^{\text {nd }}$ - and $3^{\text {rd }}$-generation are currently in use in gas turbines; but factors such as the high cost of Re have led to reduced interest in the $3^{\text {rd }}$ generation alloys. Whether or not the more advanced alloys proceed to commercialization depends on further work to characterize properties and long-term structural stability. As a result of the work to optimize compositions, and the development of multi-step heat treatments to optimize the phase content, all of the SC alloys are characterized by very high volumes of the $\gamma^{\prime}$ strengthening phase (60-70\%), and therefore exhibit incremental increases in strength at high temperature. For example, the experimental alloy TMS162 (developed in the High-Temperature Materials 21 project in Japan ${ }^{4}$ ) exhibits a rupture life of about $1,250 \mathrm{~h}$ at $1100^{\circ} \mathrm{C}$ and $137 \mathrm{MPa}$, which is claimed to be the highest temperature capability ever recorded for a Ni-based superalloy.

A typical measure of the performance of a superalloy is its creep-rupture properties. In the examples of the stress for rupture in $1,000 \mathrm{~h}$ as a function of temperature, shown in Fig. $6,{ }^{18}$ it will be seen that the new, " $5^{\text {th }}$ " generation SC alloy TMS 162 has a temperature advantage of about $40^{\circ} \mathrm{C}$ compared with the widely-used $\left(2^{\text {nd }}\right.$ generation SC) alloy CMSX-4. However, it remains to be seen whether this temperature advantage will be sustained at longer times, that is, in conditions more representative of service. Thus, longer-term creep data will be essential in order to provide a reliable measure of the improvement in temperature capability of the new alloys.

One of the major disadvantages of SC technology has been sensitivity to defects such as 'stray' grains and low-angle grain boundaries, which can seriously degrade performance. Consequently, casting yields were frequently poor in the early days of producing SC castings of large components for power generation gas turbines. However, subsequent developments in SC alloy compositions and casting technology to increase casting yield and reduce production costs has resulted in alloys with somewhat lower strength, but greater tolerance to casting defects. An early contender in this category was CMSX-186, which was initially produced as a polycrystalline, DS alloy. The SC variant (which has additions of hafnium and boron to reduce the sensitivity to 
the presence of casting defects such as low-angle grain boundaries) can be used in the as-cast condition, further contributing to a reduction in cost compared with the higheststrength SC alloys.

Further progress ${ }^{18}$ has led to the development of alloys more adapted to large castings, such as CMSX-486, which also has additions of hafnium and boron, but otherwise is similar in composition to the second-generation alloy CMSX-4 (see Table 3). An additional advantage of this alloy is that good high-temperature properties were obtained with a double aging treatment after casting, thereby eliminating the risk of localized recrystallization during solution heat treatment. In this case (as can be seen from Fig. 6), the temperature capability is inferior to that of CMSX-4 by about $60^{\circ} \mathrm{C}$, at least on the basis of the stress for rupture in 1,000 h. However, an important point is that long-term creep rupture data are available for this alloy, as shown in Fig. 7 . It is evident that, in these testing conditions, the alloy showed good stability for longer than $10,000 \mathrm{~h}$ at temperatures between 982 and $1093^{\circ} \mathrm{C}$. The alloy has good castability, and has been used for components such as multi-vane segments (Fig. 8), where defects such as low-angle boundaries can occur. 
Table 3. Nominal compositions of advanced Ni-based airfoil alloys (all are single crystal alloy except where indicated)

\begin{tabular}{|c|c|c|c|c|c|c|c|c|c|c|}
\hline \multirow[t]{2}{*}{ Alloy } & \multicolumn{10}{|c|}{ Composition, weight percent } \\
\hline & $\mathrm{Cr}$ & Co & $\mathbf{W}$ & Mo & $\mathbf{R e}$ & $\mathrm{Ta}$ & Al & $\mathrm{Ti}$ & Hf & Others \\
\hline \multicolumn{11}{|c|}{ Conventionally Cast } \\
\hline IN738LC & 16 & 8.2 & 2.6 & 1.7 & & 1.8 & 3.5 & 3.5 & & $0.11 \mathrm{C} ; 0.01 \mathrm{~B} ; 0.03 \mathrm{Zr}$ \\
\hline IN792 & 13 & 9 & 3.9 & 2 & & 3.9 & 3.2 & 4.2 & & $0.21 \mathrm{D} ; 0.02 \mathrm{~B} ; 0.1 \mathrm{Zr}$ \\
\hline IN939 & 23 & 19 & 1.9 & & & 1.3 & 1.9 & 3.7 & & $1.1 \mathrm{Nb} ; 0.15 \mathrm{C} ; .01 \mathrm{~B} ; 0.1 \mathrm{Zr}$ \\
\hline \multicolumn{11}{|c|}{ Directionally Solidified } \\
\hline MARM27LC & 9 & 10 & 10 & 0.6 & & 3.0 & 5.5 & 1.0 & 1.5 & $0.15 \mathrm{C} ; 0.15 \mathrm{~B} \mid 9,93 \mathrm{Zr}$ \\
\hline GTD-111 & 14 & 9.5 & 3.8 & 1.5 & & 2.8 & 3 & 4.9 & 0.15 & $0.1 \mathrm{C} ; 0.01 \mathrm{~B} ; 0.15 \mathrm{Hf}$ \\
\hline ExA17 ${ }^{a}$ & 12 & 9 & 3.5 & 1.8 & $2-3$ & 4 & 3.4 & 3.9 & & \\
\hline TMD103 $^{a}$ & 3 & 12 & 6 & 2 & 5 & 6 & 6 & & 0.1 & $0 . . ; 0.015 B$ \\
\hline \multicolumn{11}{|c|}{ Single Crystal } \\
\hline PWAI480 (1 ${ }^{\text {st }}$ gen $)$ & 10 & 5 & 4 & & & 12 & 5 & 1.5 & & \\
\hline PWA1483 ( $1^{\text {st }}$ gen $)$ & 12.8 & 9 & 3.8 & 1.9 & & 4 & 3.6 & 4 & & \\
\hline René N4 ( $1^{\text {st }}$ gen) & 9 & 8 & 6 & 2 & & 4 & 3.7 & 4.2 & & $0.5 \mathrm{Nb}$ \\
\hline $\mathrm{SC} 16\left(1^{\text {st }}\right.$ gen $)$ & 16 & & & 3 & & 3.5 & 3.5 & 35 & & \\
\hline PWA1484 *2nd gen) & 5 & 10 & 6 & 1.9 & 3 & & 5.6 & & 0.1 & $8.7 \mathrm{Nb}$ \\
\hline René N5 ( $2^{\text {nd }}$ gen $)$ & 7 & 8 & 5 & 2 & 3 & 7 & 6.2 & & 0.2 & \\
\hline CMSX-4 ( $2^{\text {nd }}$ gen $)$ & 6.5 & 10 & 6 & 0.6 & 3 & 6 & 5.6 & 1.0 & 0.1 & \\
\hline CMSX-186 $\left(2^{\text {nd }} \text { gen }\right)^{b}$ & 6 & 9.3 & 8.4 & 0.5 & 2.9 & 3.4 & 5.7 & 0.7 & 1.4 & \\
\hline CMSX-486 $\left(2^{\text {nd }} \text { gen }\right)^{b}$ & 5 & 9.3 & 8.6 & 0.7 & 3 & 4.5 & 5.7 & 0.7 & 1.2 & \\
\hline René N6 ( $3^{\text {rd }}$ gen) & 4.2 & 12.5 & 6 & 1.4 & 5.4 & & 5.8 & & 0.15 & 7.2Nb;0.05C;0.004B;0.01Y \\
\hline CMSX-10 ( $3^{\text {rd }}$ gen $)$ & 2 & 3 & 5 & 0.4 & 6 & 8 & 5.7 & 0.2 & 0.03 & $0.1 \mathrm{Nb}$ \\
\hline TMS75 ( $3^{\text {rd }}$ gen $)$ & 3 & 12 & 6 & 2 & 5 & 6 & 6 & & 0.1 & \\
\hline MX4/PWA1497 (“4 $4^{\text {th” }}$ gen) & 2 & 16.5 & 6 & 2 & 6 & 8.3 & 5.6 & & 0.05 & 3Ru;0.03;0.04B;0.01Y \\
\hline TMS139 (“4 $4^{\text {th” }}$ gen) & 2.9 & 5.8 & 5.8 & 2.9 & 4.9 & 5.5 & 5.8 & & 0.1 & $31 \mathrm{r}$ \\
\hline TMS162 (“5 $5^{\text {th” }}$ gen) & 2.9 & 5.8 & 5.8 & 3.9 & 4.9 & 5.6 & 5.8 & & 0.1 & $6 \mathrm{Ru}$ \\
\hline TMS196 (“5 $5^{\text {th” }}$ gen) & 4.6 & 5.6 & 5.0 & 2.4 & 6.4 & 5.6 & 5.6 & & 0.1 & $5 \mathrm{Ru}$ \\
\hline
\end{tabular}

${ }^{a}$ Developmental alloy.

${ }^{b}$ Revisited $2^{\text {nd }}$ generation. 


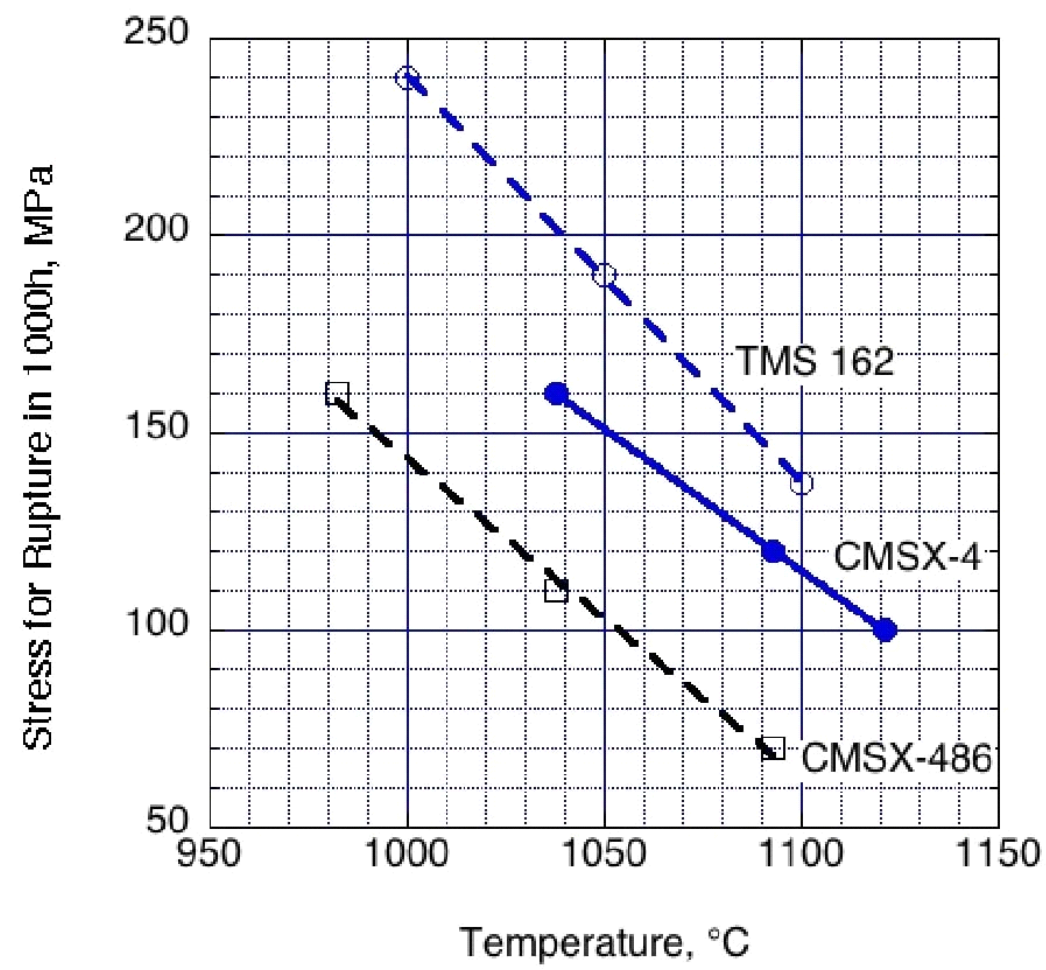

Fig. 6. Stress for rupture in $1,000 \mathrm{~h}$ as a function of temperature for single-crystal alloys (after Harris and Wahl, ref. 18).

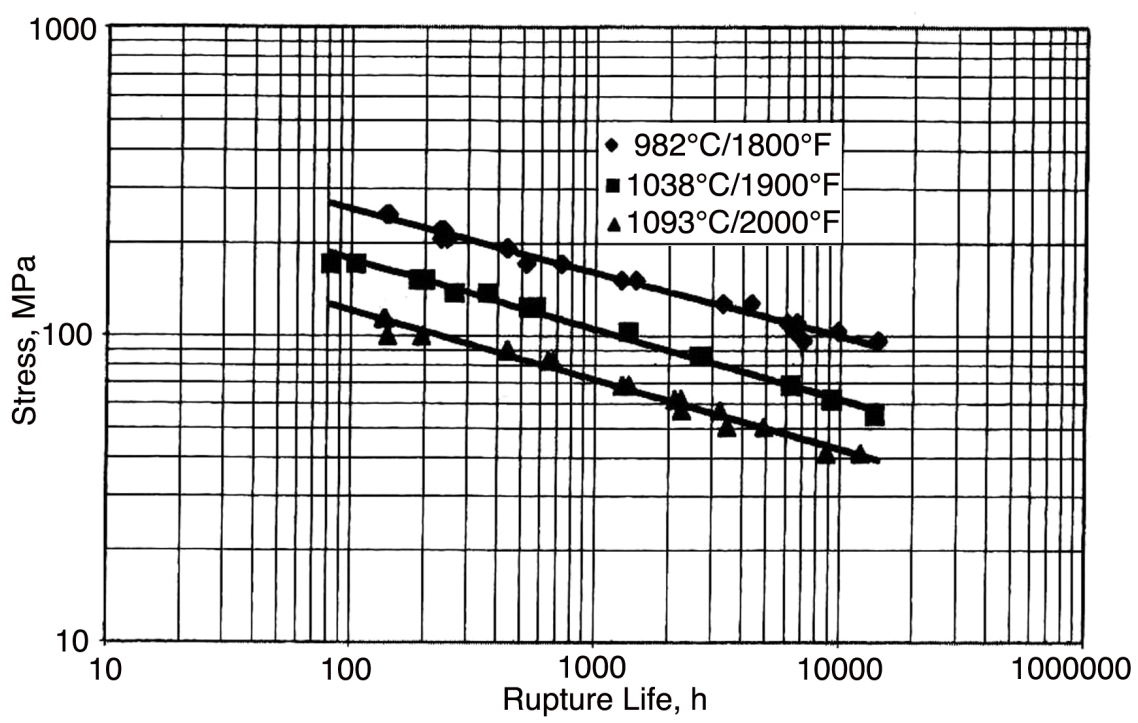

Fig. 7. Creep rupture properties of single-crystal alloy CMSX-486 (after Harris and Wahl, ref. 18). 


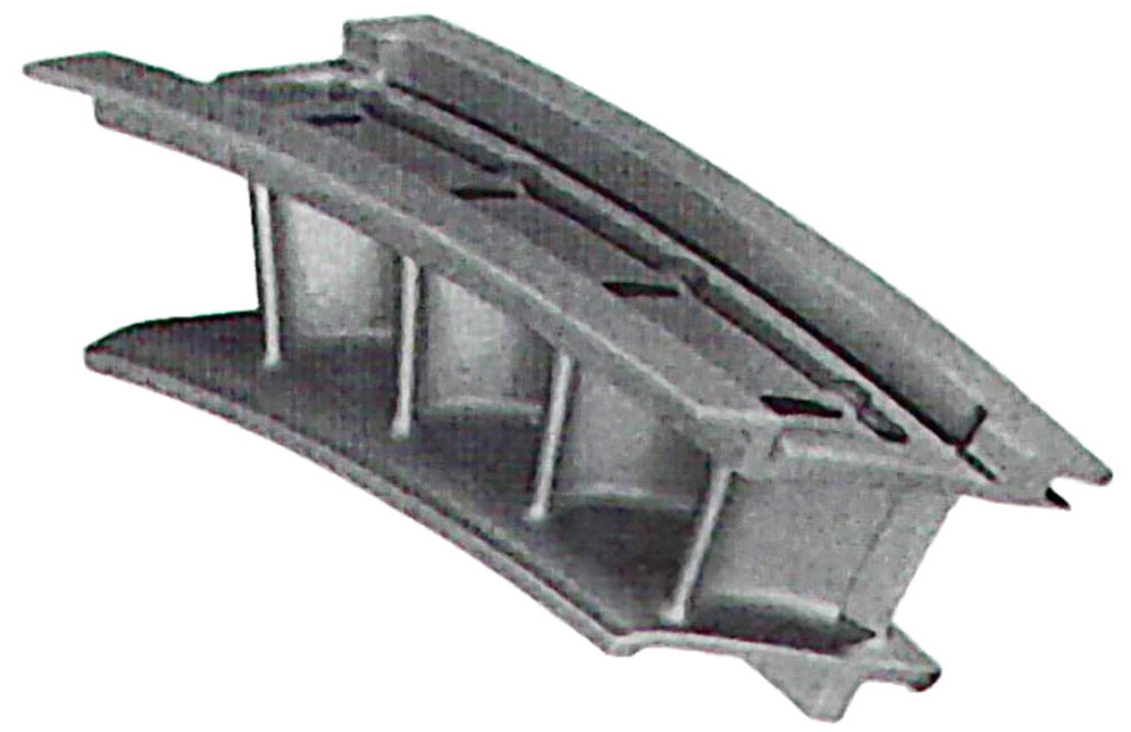

Fig. 8. An example of a second stage vane quadruplet cast as a single-crystal (courtesy of G. McColvin, Siemens).

Other similar work in Japan aimed at developing single-crystal alloys for power generation gas turbines ${ }^{19}$ also involved slight modifications to the composition of second-generation alloys and, while some improvement in creep strength was obtained, there was little gain in terms of hot corrosion, or oxidation resistance. Also, since a full solution treatment was necessary, there was no benefit from a simpler heat treatment. Recent advances have been made to increase the strength capabilities of SC superalloys intended for both power generation and aircraft applications, with further developments of " $5^{\text {th" }}$ generation alloys with claimed improvements in creep temperature capability, fatigue life, and phase stability compared to currently-used $2^{\text {nd }}$ generation alloys. ${ }^{20,21}$ While these advances were aimed at combining higher temperature capabilities with an improved balance of properties, the impact on cost and castability to date has been sufficiently negative to significantly inhibit movement toward commercialization. Nevertheless, developments in high solidification rate SC casting processes using liquid metal cooling recently have been demonstrated for alloys such as PWA 1483 and CMSX $-4^{22}$ that promise improved control of alloy microstructure that has positive implications for reproducibility of properties, and reduction in component cost. 
A characteristic of all the alloys discussed above is that, while the compositions have been optimized for high-temperature creep strength, the main environmental threat considered was that from high-temperature oxidation. These alloys rely on an inherent ability to form a protective scale based on alumina and, since the alloy content of chromium is relatively low, they will have poor resistance to sulfidation (hot corrosion) if sulfur and alkali levels in the fuel are higher than those in natural gas. Accordingly, it may be necessary to develop a new range of higher-chromium alloys with good creep resistance for operation in syngas environments. This will be a challenging requirement, because lowering the chromium level has been critical to the success of the development of the high-strength levels in SC alloys.

Since not all gas turbines are required to operate at the highest RIT, and not all components in the engine (for example, the later stages of the turbine) are exposed to the highest temperatures, there is a continuing effort to improve the performance of DS alloys with columnar-grained microstructures. One consequence of the lower temperatures experienced by these components is that they operate in a regime where they are susceptible to Type I hot corrosion ${ }^{23}$ if condensable sulfate impurities are present in the combustion gas. Type I hot corrosion involves sulfidation attack from deposits of molten salts (typically based on $\mathrm{Na}_{2} \mathrm{SO}_{4}$ ). The guiding principle in alloy selection for resistance to this form of corrosion is to maximize chromium content; alloys specifically designed to combat hot corrosion, such as IN738, IN939 and GTD-111, contain 14-23 wt \% chromium (Table 3 ). Thus, a logical goal for improved DS alloys is to achieve corrosion and oxidation resistance equivalent to IN939, and creep strength superior to that of alloy MARM247 (which has been widely used as a blade and vane material in large gas turbines). The emphasis of recent work ${ }^{24}$ was on the concept of adding rhenium to alloys with relatively high chromium contents (around 10\%), and the outcome was an experimental alloy ExA17 with good resistance to hot corrosion and oxidation and, that was (following a homogenizing heat treatment) substantially free of harmful phases that would result in structural instability. Early results from creep tests suggest that the improvement in creep strength will be equivalent to an increment in temperature capability of about $30^{\circ} \mathrm{C}$ relative to the performance of the standard MARM247LC.

A somewhat different approach has been adopted in Japan: ${ }^{25}$ in this case, $5 \%$ rhenium was added to an alloy with a low content of chromium and, in relatively short-term tests $(6,000 \mathrm{~h})$, the creep performance of the alloy (TMD103) approached that of the SC alloy TMS75. The compositions of these new alloys are included in Table 3, 
along with that for MARM247LC for comparison. Thus, it appears that there remains some potential for further improvement in the performance of DS alloys.

These developments should be seen in the context of the effort to push the superalloys to the limit of their capabilities in the absence of any likely successor material at least in the foreseeable future.

\subsection{COATINGS FOR HP BLADES AND VANES}

The high rotor inlet temperatures of current land-based gas turbines are achieved by a combination of cooling processes, usually using air bled from the compressor, and the application of TBCs to provide thermal insulation. Together, these technologies are used to maintain maximum metal temperatures at around $1000^{\circ} \mathrm{C}$ (while RITs approach $1450^{\circ} \mathrm{C}$ ). This relationship is illustrated in Fig. $9 .^{26}$ The effort to bridge the increasing gap between alloy creep strength and gas temperature has led to the development of innovative combinations of cooling technology and TBCs to enable continued improvements in gas turbine performance.

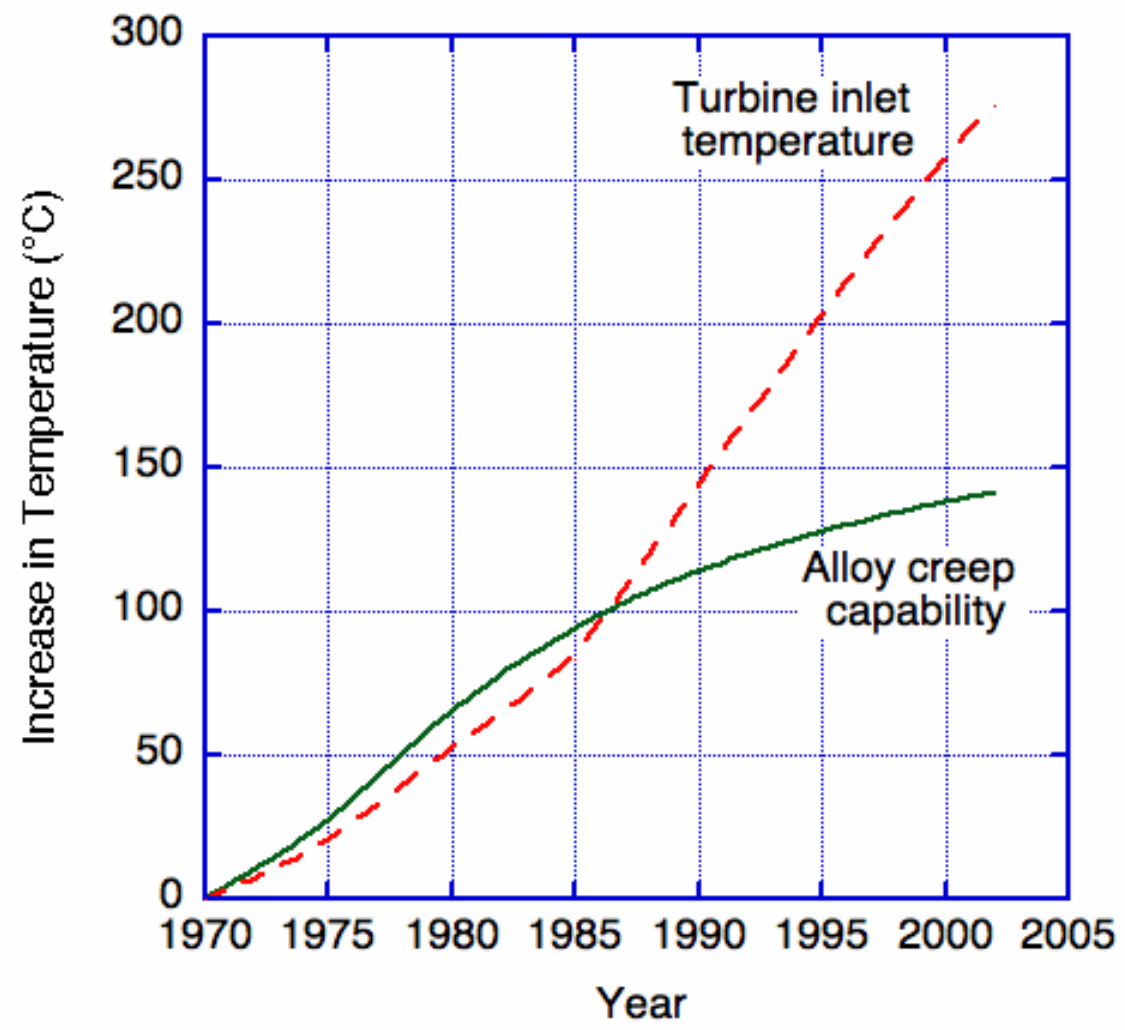

Fig. 9. Comparison of trend in material temperature capability and turbine inlet temperature for aero-gas turbines (after Walston, ref. 26). 
Initially, TBCs were used to give an extra measure of protection (as well as enhancement of component life) for an existing design but, increasingly, components have been designed to take some advantage of the temperature decrement provided by the coating system. Increasingly, the full functioning of the TBC is essential for the engine to meet performance targets. In order to achieve this objective, an unprecedented level of reliability and consistency of performance is required. Consequently, a major effort is being devoted worldwide to understanding the failure mechanisms of TBCs, with the aim of achieving the degree of predictability needed to allow the confident use of mechanism-based lifting models, with the hope of eventually attaining the goal of being able to take full advantage of the temperature decrement provided by a TBC in engine design. In parallel with this development, non-destructive evaluation (NDE) techniques are being devised to enable the condition of the coating to be monitored (preferably in-situ) to provide early indication of coating deterioration. ${ }^{2}$

For most types of gas turbines operating with relatively clean fuels (aviation fuel/kerosene or natural gas), where oxidation is the main degradation mechanism, a modern coating system consists of a thin, metallic coating (bond coating, $50 \mu \mathrm{m}$ thick), usually an aluminide [NiAl or (Ni,Pt)Al] formed by diffusion, or a MCrAlY type overlay (where $\mathrm{M}$ can be $\mathrm{Ni}$, Co or $\mathrm{NiCo}$ ) applied to the substrate; and a layer of ceramic, typically yttria-stabilized zirconia, applied on top of the bond coating. The ceramic layer on rotating parts usually is approximately 125 to $250 \mu \mathrm{m}$ thick, but strong interest in increased thermal resistivity has spurred significant interest in ceramics such as $\mathrm{Gd}_{2} \mathrm{Zr}_{2} \mathrm{O}_{7}$, and thicker ceramic layers on non-rotating parts.

The purpose of the bond coating is threefold: (1) to provide an anchoring surface for the ceramic layer; (2) to give oxidation protection (since zirconia allows rapid transport of oxygen); and (3) to offer some resistance to other forms of corrosion that could include oxidation-sulfidation (from gaseous sulfur contaminants in the combustion products) and hot corrosion (from the presence of deposits of molten alkali sulfates), should the requisite corrodents gain access to the metallic surface if the ceramic layer is breached. Figure 10 shows a schematic representation of this type of coating system. The composition of the ceramic layer is optimized for good structural stability and toughness as well as reduced thermal conductivity. Currently, while the reliability of TBC systems has increased significantly, there remains sufficient variability that some TBC systems are as yet insufficiently robust to give predictable performance in the long term. 


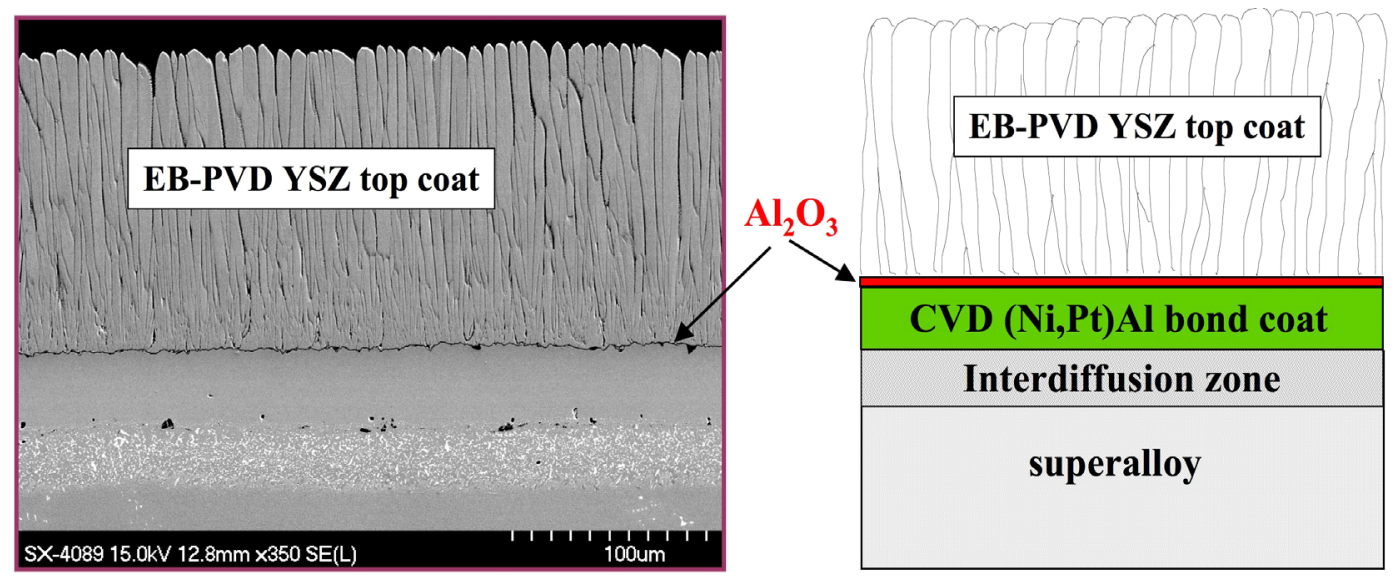

Fig. 10. Micrograph and schematic diagram showing the various layers in a TBC system (after Haynes, ref. 27).

Failure of a TBC system often occurs either by debonding along the interface between the bond coating and its thermally-grown protective oxide (TGO, preferably $\alpha-\mathrm{Al}_{2} \mathrm{O}_{3}$ ) layer (which bonds to the zirconia), or as a result of decohesion of the ceramic layer (usually near the interface with the TGO. ${ }^{28}$ Mechanical disruption (rumpling) of certain bond coatings also can occur as a result of volume changes associated with a temperature-induced phase change, which can lead to significant displacement of the bond coating-TGO and TGO-ceramic interfaces, and failure of the TBC. ${ }^{29,30}$ Adhesion between the bond coating and the TGO has been enhanced as a result of understanding the need to optimize the levels of minor elements in the bond coating and in the superalloy. Tramp elements such as sulfur have been shown to be detrimental to TGO adherence, ${ }^{31,32}$ so that alloying practices have been developed that routinely achieve sulfur levels as low as $1 \mathrm{ppm}^{32}$ Controlled additions of reactive elements such as yttrium and hafnium also can be used to counter the effects of sulfur, ${ }^{33}$ such additions have been shown also significantly to modify the growth mechanism of the TGO and reduce its rate of growth, as well as to decrease its tendency for spallation, all of which promise to extend TBC lifetimes. ${ }^{34}$ Some interpretations of the rumpling phenomenon have prompted efforts to strengthen the bond coating or to use thinner bond coatings, with the intention of increasing resistance to fatigue deformation. ${ }^{34}$ Overall, improvements in understanding of the mechanisms of TBC degradation are providing routes for further improvements in their durability.

There has been interest in eliminating the bond coating and applying the ceramic layer directly on top of the TGO formed on the surface of the component. In fact, it has been suggested that the life of a TBC system could be improved if the bond coating 
were eliminated, because the TGO formed on the substrate would benefit from the strength of the underlying alloy, and thus have a greater resistance to buckling during thermal cycling. ${ }^{26}$ While this approach can reduce cost (and weight), the integrity of the coating will depend on the ability of the alloy to grow an oxide layer with an appropriate combination of properties. One potential drawback of the 'bond coating-less' approach is the potential for increased loss of alloy thickness (compared to that when a bond coating is present) during overhaul, when the surface coatings are stripped off and replaced or refurbished.

Much effort has been focused on the deposition routes used for TBCs, especially on ensuring that the desired coating compositions and structures are achieved. The cost of coating is of major importance and, in this respect, processes that are amenable to robotics and do not require the use of vacuum chambers have an advantage. However, coatings synthesized by electron-beam physical vapor deposition (EB-PVD) appear to have superior durability in some applications, possibly because of their columnar microstructure that is claimed to give some capability to resist thermal fatigue. ${ }^{35}$ Significant effort has been devoted to sprayed coating processes to develop procedures for mimicking this apparently desirable microstructure. A potentially detrimental issue is the possibility that the interfaces between the columnar grains can provide paths for diffusion of corrosive species, such as sulfur compounds, to the surface of the bond coating (or superalloy). Also, deposits of CaMgAl-silicates (CMAS) of variable composition, and containing small amounts of iron and nickel oxides, can form on the outer ceramic surface and react to form a solid layer, which is deleterious to the performance of the coating regardless of microstructure ${ }^{36}$ In order to improve the durability of the ceramic layer, it has been proposed that an environmentally-protective coating should be applied to its outer surface. ${ }^{37}$ Demonstration of improved resistance to CMAS by new ceramics such as $\mathrm{Gd}_{2} \mathrm{Zr}_{2} \mathrm{O}_{7}$ could spur their introduction into service.

Other activities aimed at further improvement to TBC systems have included increasing the toughness of the ceramic layer to reduce mechanical damage as a result of particle impact during operation ${ }^{34}$ and, recently, modifications to the ceramic composition to reduce thermal conductivity, so that thinner TBCs or higher gas temperatures could be used. ${ }^{38}$ However, modifications in composition to reduce thermal conductivity by adding increased amounts of yttria typically tend to reduce fracture toughness and consequently may affect erosion resistance. Consequently, it appears that the 'Holy Grail' continues to be alternative ceramic materials for the thermal barrier 
layer that combine low thermal conductivity with good fracture toughness and excellent phase stability.

For second and subsequent rows of blades and vanes (where metal temperatures are lower), full coverage of the aero-foil surface with a TBC may not be necessary and, where corrosion protection is required, an overlay coating of the NiCoCrAlY type is usual. The composition of such coatings can be tailored for the specific alloy to be protected and the corrosive conditions expected; for instance, where oxidation resistance at temperatures above about $850^{\circ} \mathrm{C}$ is required, a composition such as $\mathrm{Ni}-22 \mathrm{Co}-20 \mathrm{Cr}-12 \mathrm{Al}-0.2 \mathrm{Y}$ (in weight percent) would be used. The aluminum content is a balance between the need to form a continuous, adherent TGO with an adequate reservoir of aluminum, and embrittlement (and a tendency to spalling) with excessive aluminum levels. Where attack by sulfidation-oxidation or hot corrosion is a risk, the level of chromium in the coating would be increased, and the aluminum decreased. Thus, while the details of the composition of the coating are often proprietary to the engine manufacturer, generally the composition is optimized to give adequate oxidation or corrosion resistance while maintaining a minimum level of ductility.

\subsection{COMBUSTOR MATERIALS}

Traditionally, combustor components have been fabricated from Ni-base alloys produced in sheet form. Widely-used alloys are Hastelloy $X$ and Alloys 617 and 230 (compositions in Table 4). The key characteristics of these materials are:

1. good formability;

2. little tendency for post-weld heat treatment cracking;

3. good high-temperature properties (creep strength, thermal fatigue resistance, oxidation resistance); and

4. no requirement for heat treatment after repair welding.

Table 4. Compositions of typical sheet alloys (in weight percent)

\begin{tabular}{lccccccccccccc}
\hline \multicolumn{1}{c}{ Alloy } & $\mathrm{Cr}$ & $\mathrm{Co}$ & $\mathrm{Mo}$ & $\mathrm{W}$ & $\mathrm{Mn}$ & $\mathrm{Al}$ & $\mathrm{Ti}$ & $\mathrm{Si}$ & $\mathrm{Fe}$ & $\mathrm{C}$ & $\mathrm{B}$ & La & $\mathrm{Ni}$ \\
\hline Hastelloy X & 22 & 1.5 & 9 & 0.6 & $1^{\mathrm{a}}$ & -- & - & $1^{\mathrm{a}}$ & 18 & 0.1 & $0.008^{\mathrm{a}}$ & -- & bal \\
617 & 22 & 12.5 & 9 & -- & $1.0^{*}$ & 1.2 & $0.6^{\mathrm{a}}$ & $1.0^{\mathrm{a}}$ & $3^{\mathrm{a}}$ & 0.1 & $0.006^{*}$ & -- & bal \\
230 & 22 & $5^{\mathrm{a}}$ & 2 & 14 & 0.5 & 0.3 & -- & 0.4 & $3^{\mathrm{a}}$ & 0.1 & 0.015 & 0.02 & bal \\
\hline
\end{tabular}

${ }^{a}$ Maximum 
Approaches for maintaining metal temperatures at acceptable levels (around $950^{\circ} \mathrm{C}$ ) involve the combination of cooling air and TBCs, or the use of ceramic tiles. Such components have generally performed well in most types of gas turbine, but with further increases in firing temperature likely, and more complex combustion conditions, there has been some effort to evaluate alternative materials. Among these, both oxide dispersion-strengthened (ODS) ferritic alloys (such as PM2000) and ceramic-matrix composites have been considered. Some success has been achieved with $\mathrm{SiC}-\mathrm{SiC}$ as well as oxide-oxide ceramic-matrix composites, ${ }^{39}$ and engine trials have been carried out on components manufactured from this type of material. ${ }^{40-42}$ An example of a ceramic composite combustor liner is illustrated in Fig. 11.

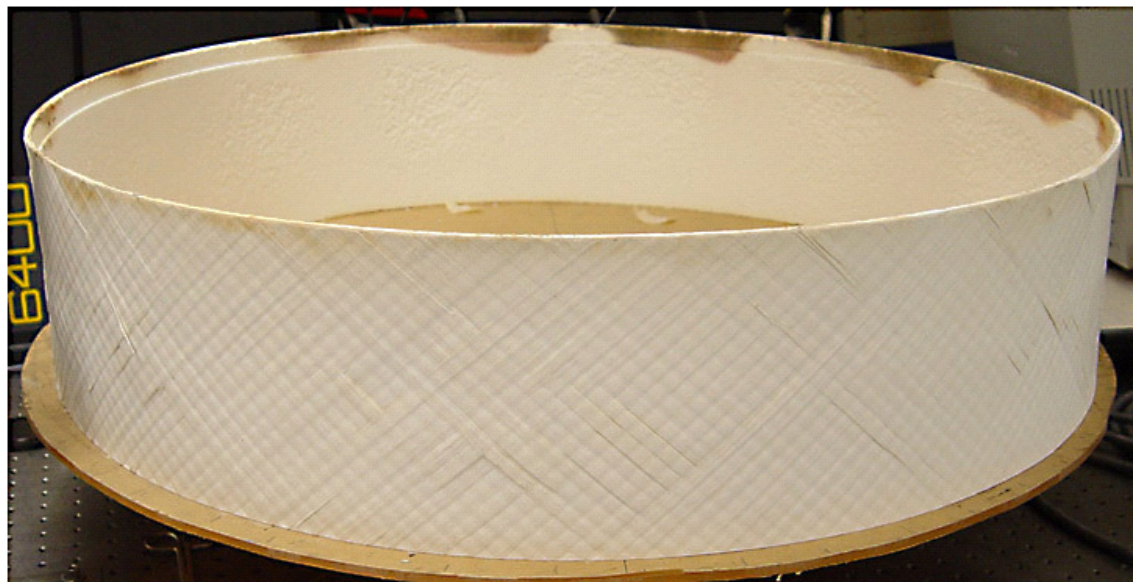

Fig. 11. Combustor liner manufactured from ceramic composite (courtesy of G. McColvin, Siemens).

\subsection{DISC ALLOYS}

Since weight has normally been a less important parameter in large gas turbines for power generation than in aero-engines, turbine discs or rotors have frequently been manufactured from $12 \% \mathrm{Cr}$ steels, and advanced versions of these alloys have been introduced as strength requirements have increased. However, for the highesttemperature conditions in the high-pressure turbines of modern gas turbines, there has been a tendency for Ni-base alloys to replace the ferritic steels. One alloy with the appropriate balance of properties for this application is IN706, which is a "lean" version of alloy IN718 which is widely used in aero-engines. The compositions of the two alloys are given in Table 5 . 
Table 5. Compositions of typical Ni-base disc alloys (in weight percent)

\begin{tabular}{cccccccccc}
\hline Alloy & $\mathbf{C r}$ & Co & Mo & Nb & \multicolumn{1}{c}{ Al } & Ti & Ni & C & Bal \\
\hline IN706 & 16 & $1.0 \max$ & - & 3 & $0.4 \max$ & 1.75 & 31.5 & $0.06 \max$ & $\mathrm{Fe}$ \\
IN718 & 19 & $1.0 \max$ & 3 & 5 & 0.5 & 0.9 & 53 & $0.08 \max$ & $\mathrm{Fe}$
\end{tabular}

A crucial difference between the aero and the power generation turbine is the size of the high-pressure turbine disc, which can be up to $1.5 \mathrm{~m}$ in diameter in the latter case. Consequently, successful fabrication of large forgings from $\mathrm{Ni}$-base alloys required a significant development effort [see, for instance, reports from General Electric's program, references], ${ }^{43-46}$ which was focused on four main requirements, viz:

- freedom from segregation in large forgings;

- hot workability within the capacity of existing forging equipment;

- better machinability than IN718; and

- no increase in costs compared to IN718.

In order to achieve these objectives, the alloy composition was modified to improve fabricability (forging, machining, and welding), while maintaining strength and phase stability to ensure adequate toughness. As a result of careful control using advanced melting techniques, ingots free of macro-segregation can be produced. These are then forged and heat-treated to optimize mechanical properties. However difficulties remain and Ni-base alloys are not yet widely used for discs in large gas turbines. Nevertheless if higher gas temperatures are necessary for improved efficiency, Ni-base alloys will be necessary and further development work will be inevitable.

\subsection{PREDICTION OF MATERIALS PROPERTIES BY COMPUTER MODELING}

With the continuing drive to reduce costs and design cycle time in the manufacture of power plant equipment, there has been an increase in the need for more sophisticated materials property data. For example, in gas turbine components (particularly blades and vanes), long-term creep data are required to support designs for component lifetimes of 20,000 h or more. Similarly, the increased need for cyclic capability (even in nominally base-loaded plant) has focused attention on the requirement for fatigue data, including thermo-mechanical fatigue. 
The test programs required to obtain such data are time-consuming and expensive to execute. The availability of modeling techniques to supplement or to define critical test parameters would be of enormous benefit in increasing the efficiency of such mechanical testing programs. Modeling techniques based on thermo-chemical approaches are widely used in the design of new alloys, and are replacing the old trialand-error methods which often were inefficient and time consuming. Similarly, models based on fluid flow and on high-temperature plasticity are now used to define optimum casting conditions for components such as turbine blades, and for optimizing forging processes for discs and other forged products, respectively. ${ }^{47}$ The greatly-increased computing power now widely available has been a key factor in enabling the successful application of these modeling techniques to industrial processes, and has been instrumental in reducing cycle time and costs.

In contrast, the application of computer-based modeling methods to the prediction of materials properties and component performance at high temperatures has progressed rather more slowly. Similar comments apply to the use of accelerated testing techniques, such as those advocated by Woodford. ${ }^{48}$ However, it is likely that the use of predictive techniques and accelerated testing will become more widespread as confidence in the methods increases, and demand grows for more sophisticated measures of materials performance.

A thermodynamics-based approach to the prediction of physical properties for superalloys (such as Young's Modulus and linear expansion), that has recently been described, ${ }^{49}$ is based on physical principles rather than on statistical methods. Calculated values have shown good agreement with experimental measurements for wrought Ni-base alloys. This seemingly versatile approach has been used to calculate TTT diagrams, as well as values of proof stress and creep rates, with encouraging agreement with experimental measurements in each case.

Several techniques have been proposed for prediction of mechanical properties (particularly creep) at high temperatures. Probably the most appealing method is that of employing physically-based continuum damage mechanics (CDM), which uses quantitative models of the deformation and fracture mechanisms in the creep regime to develop a methodology for predicting creep in engineering alloys. A multiaxial variant approach can be applied as a sub-routine in a finite-element program to predict the lifetime in creep of simple components. ${ }^{50,51}$ Because it can be shown that other wellknown methods (such as the Larson-Miller parameter and the Omega parameter) can be derived from a CDM analysis, it is evident that this methodology provides a unifying 
framework within which apparently unrelated life-prediction methods can be rationalized. The application of the technique in the prediction of the creep behaviour of superalloys, ${ }^{52}$ and of ferritic steels and simple power plant components, ${ }^{53}$ recently has been described.

The ultimate aim in the context of component lifetime prediction should be to integrate the various modeling techniques, so that an optimized casting design (for example, for a turbine blade) could then be subjected to a computer-based life prediction analysis. If such a process were carried out on an iterative basis, one can envision a situation where a component designed for castability would require only limited testing to demonstrate satisfactory performance. 


\section{IMPLICATIONS FOR MATERIALS SELECTION IN GAS TURBINES BURNING SYNGAS OR HYDROGEN}

\subsection{PERFORMANCE TARGETS}

The U.S. Department of Energy (DOE) recently has outlined performance targets for turbines burning coal-derived gas. ${ }^{54}$ These targets are summarized in Table 6 , and it will be seen that these are nominally less demanding than the current performance of advanced natural gas fired machines. However, the combustion of gas produced by coal presents several additional problems not usually encountered with natural gas, and these may have implications for performance and component design. As previously discussed, while natural gas contributes about $2 \%$ of the overall fluid flow through the engine, low-Btu syngas will contribute about $15-20 \%$, and modifications must be made to the compressor to accommodate this increased mass flow. Also, flame speed can be increased due to the higher hydrogen content of syngas, and this can cause difficulties in controlling combustion. Furthermore, since flame temperatures will be higher in these conditions (Table 1), $\mathrm{NO}_{\mathrm{x}}$ control will be more difficult, so that meeting the emissions targets could be challenging.

Table 6. U.S. DOE performance targets for gas turbines burning coal-derived gas

\begin{tabular}{|c|c|c|c|c|}
\hline Fuel & Target Date & $\begin{array}{c}\text { Efficiency Target } \\
\% \text { (HHV) }\end{array}$ & $\mathrm{NO}_{\mathrm{x}},\left[\mathrm{CO}_{2}\right](\mathrm{ppm})$ & Cost $(\$ / k W)$ \\
\hline Syngas & 2010 & $\begin{array}{l}2-3 \% \text { better than } \\
\text { FB-frame engines } \\
\text { on syngas (45-50 } \\
\text { overall IGCC) }\end{array}$ & $\begin{array}{l}<2 \text {; ['capture } \\
\text { ready'] }\end{array}$ & $\begin{array}{l}20-30 \% \\
\text { improvement }\end{array}$ \\
\hline $100 \% \mathrm{H}_{2}$ or syngas & 2012 & 60 & Near zero; [0] & $\begin{array}{c}<10 \% \text { increase } \\
\text { over current plants }\end{array}$ \\
\hline Oxygen/multifuel & 2012 & $50-60$ & $0 ;[100 \%$ capture] & - \\
\hline
\end{tabular}

\subsection{FUEL-RELATED CORROSION}

The major areas of difficulty for materials performance in applications involving syngas are likely to be those associated with the specific characteristics of the combustion environment, especially the type and amount of minor species present in the fuel, viz: 
- the increased content of water vapor in the combustion gas, resulting not only from the composition of the fuel gas but also from water scrubbing during clean up;

- the sulfur level, depending on the level of clean up and the efficiency of the process; and

- the particulate content, which is expected to be very low from clean-up scrubbing processes, but will vary depending on the functioning of those processes with the possibility of very high levels being attainable (albeit for relatively short times) during plant upset conditions.

In each case, the value of these parameters is expected to be higher than for turbines fired with natural gas, and could have an important influence on component performance. Thus, there is a need for detailed information on the actual compositions of the gas produced from the various gasifier technologies, with emphasis on critical impurity levels and on particulate loading, so that the implications for component performance can be assessed realistically. Despite the expectation that the syngas entering the turbine will be at least as clean as demanded by the gas turbine manufacturers' fuel specifications, it will be important to understand the possible ranges of impurities so that regimes of actual fuel compositions can be defined for safe operation.

In recent studies, ${ }^{55,56}$ it has been shown that the presence of water vapor $(0.1$ to $0.5 \mathrm{~atm}$.) could adversely affect the oxidation resistance of both chromia- and aluminaforming alloys at temperatures between 700 and $900^{\circ} \mathrm{C}$. For alumina-forming alloys, the presence of water vapor reportedly had an adverse effect on the ability to form the desired protective scale ( $\alpha$-alumina, ) particularly at lower temperatures; there was some tendency for the less-protective transient oxides to form, even at the higher temperatures where $\alpha$-alumina is expected. Interestingly, a diffusion ( $\mathrm{Ni}, \mathrm{Pt}) \mathrm{Al}$ coating performed well in moist air. ${ }^{55}$ Further, in the presence of high trace levels of sulfur in the substrate, there was an increased tendency for the oxide to spall.

In the case of chromia-forming alloys, the formation of the volatile oxyhydroxide, $\mathrm{CrO}_{2}(\mathrm{OH})_{2}$ at temperatures as low as $600^{\circ} \mathrm{C}^{57}$ leads to accelerated oxidation and scale spallation from the typical $18 \mathrm{Cr}-12 \mathrm{Ni}$-class of austenitic steels. Steels with higher $\mathrm{Cr}+\mathrm{Ni}$ levels, and most chromia-forming Ni-base alloys experience an increased rate of loss of $\mathrm{Cr}$, which will result in reduced oxidation lifetimes. At $900^{\circ} \mathrm{C}$, it was apparent that the 
well-known tendency for $\mathrm{Cr}_{2} \mathrm{O}_{3}$ to evaporate as $\mathrm{CrO}_{3}$ was exacerbated in wet air, due to the formation of $\mathrm{CrO}_{2}(\mathrm{OH})_{2}$.

It is well known that alkali sulfates can cause corrosion of superalloys at high temperatures when they are deposited as molten species. ${ }^{23}$ Such 'hot corrosion' has been of less concern for turbines burning low sulfur-content natural gas, in which oxidation is the principal degradation process, and current coatings have been developed accordingly. With the higher sulfur levels anticipated in coal-derived fuels, this straightforward scenario is likely to change, particularly in units on sites near the sea where atmospheric $\mathrm{NaCl}$ levels will be higher. With cold syngas clean-up, it is expected that species present as condensable vapors (and solid particles) will be essentially eliminated before the gas enters the turbine, so that the main concern (in addition to water vapor) will be condensable species in the combustion air, and non-condensable species (such as sulfur-containing gases) in the fuel gas. With warm or hot gas cleanup, the performance of the filtration and sulfur-removal systems will control not only the amounts and types of condensable species that survive and pass into the combustor, but also the size and concentration of solid particles derived from the gasifier. Thus, a better definition of the allowable maximum concentrations (and size distributions) of each contaminant for acceptable turbine life, for the range of gasifier/clean-up designs and fuel types considered, would be prudent.

In terms of providing protection from sulfur-related corrosion, the coatings developed to provide protection for natural gas-fired turbines typically are deficient in chromium, the major element needed to counter sulfidation and hot corrosion attack. The surfaces of the high pressure turbine stages that are covered by TBC The surfaces of the high-pressure stages that are covered by TBCs likely will run at temperatures above the condensation temperatures of salts associated with hot corrosion, so that molten salt attack from that source is considered unlikely, except at the cooler airfoil roots. Nevertheless, degradation from physical deposition of CMAS (mentioned earlier) remains an issue, but this may be countered by the newer ceramics being developed for TBCs. Corrosion protection from metallic coatings probably will be needed for the later turbine stages, where surface temperatures will fall into the range where condensed salt deposits can form; the compositions of the structural alloys used for these stages are unlikely to confer inherent resistance to hot corrosion. Overall, coping with the risk of high-temperature degradation is expected to be a major consideration in syngas-fired gas turbines, and extensive development work on coatings systems will be required. 
While the potential for erosion and/or deposition from the combustion of syngas is expected to be essentially eliminated if the cold gas clean-up systems operate as designed, the turbine manufacturers are mindful of the potential damage from the presence of high-velocity particles. As a consequence, there is interest in approaches (should they be needed) for guarding against surface erosion of hot gas path parts, particularly of TBCs on airfoil leading edges; and blocking of cooling holes on blades and vanes which could impair cooling efficiency.

\subsection{MATERIALS SELECTION}

From the information presented in the preceding sections of this review it will be evident that the alloys available or currently under development for hot-gas-path components would in principle be expected to meet the requirements in terms of strength and long-term stability for similar applications in engines burning low-Btu gas. Thus for components such as blades and vanes, combustors and rotors and discs, alloys are available with performance characteristics appropriate for the syngas application.

However an important limitation lies in the ability of these materials to demonstrate long-term durability in environments that may be more corrosive due to increased sulfur levels, and where the presence of particulates could cause loss due to erosion of coatings, which are critical to component longevity. Alloys and coatings currently used in engines burning natural gas have been designed to resist oxidation in relatively clean environments. Since sulfur levels will undoubtedly be higher in syngas combustion environments, the need for a high-strength single-crystal alloy with good resistance to sulfidation attack when coatings are breached will almost certainly emerge. Equally, the current generation of oxidation-resistant coatings may have to be augmented by coatings with greater sulfidation resistance, which typically is equated with higher levels of chromium. The development of alloys and coatings with the capability of operating at high temperatures while maintaining good compatibility with the substrate alloys in sulfidizing environments will represent a considerable challenge to the materials community.

Furthermore, if engines burning syngas are required to operate at efficiencies comparable to those of turbines burning natural gas, a significant increase in firing temperatures will be necessary and, since it is likely that materials for critical 
components will be limited to superalloys for the foreseeable future, novel component designs and improved TBCs will be required to cope with the more demanding conditions. An example of a design for a component with a higher-temperature capability was reported recently, and is being developed in a German national program. ${ }^{58}$ The so-called core and skin design has been proposed before, and has the advantage that cooling channels can be located very close to the component surface, thereby maximizing the impact of the cooling air. This work is at an early stage, but may indicate the type of approach required for these very demanding conditions. Similarly, disc alloys with enhanced performance will be required, since the martensitic steels will not withstand the projected higher temperatures. Consequently, further development of suitable Ni-base alloys will be necessary in order to establish fabrication methods for large, high-strength discs with microstructures that give high defect tolerance and good structural integrity. For combustors and burners, wider application of ceramic and ODS materials may be necessary.

The oxygen/multifuel target indicated in Table 6 is being addressed in a program that uses combustion technology developed by Clean Energy Systems and turbine technology from Siemens Power Generation. ${ }^{59}$ The combustion conditions discussed concerning the development of the oxygen/syngas/hydrogen combustor ${ }^{60}$ raise some potentially challenging issues for materials selection. The fully-developed combustion process is envisioned to deliver steam- $\mathrm{CO}_{2}$ mixtures at temperatures and pressures ranging up to $1760^{\circ} \mathrm{C}$ and $22 \mathrm{MPa}$ into the turbine, which will require either a major revision of the cooling technology applied to the first stages of vanes and blades, or possibly the use of ceramics. A further issue is that there is very little experience of the compatibility of available high-temperature materials with steam and steam- $\mathrm{CO}_{2}$ mixtures at such extreme conditions.

Earlier studies in support of the Japanese-sponsored World Energy Network Program (WE-NET), ${ }^{61}$ which involved combustion of hydrogen and oxygen in a gas turbine at temperatures up to $1700^{\circ} \mathrm{C},{ }^{62}$ highlighted the need for advanced cooling concepts, especially for the combustor and transition ducting, and for information on the operability of the combustor. The major materials issues identified were associated with the durability of Ni-based superalloys with appropriate corrosion-resistant coatings and TBCs; concerns ranged from hydrogen embrittlement, stress corrosion cracking, and creep rupture to oxidation and corrosion deposits. 
Depending on the final choice of materials and the exact nature of the environmental conditions, there may be a requirement for improvements in the property database, particularly for long-term creep and fatigue data. In this connection, it may be possible to obtain useful support from the current projects supported by the U.S. Department of Energy on, for instance, materials for applications in ultra-supercritical steam where work on selected Ni-base superalloys includes the generation of long-term data on properties at high temperatures. ${ }^{63}$ Also, the results of work at the Oak Ridge National Laboratory to develop a broadly based compilation of materials property data ${ }^{64}$ using the Granta System ${ }^{65}$ will provide a valuable resource. 


\section{SUMMARY OF MATERIALS NEEDS}

For all fuel scenarios considered, it is apparent that increased turbine operating temperatures will be required, so that materials with higher temperature capabilities are a necessity. A distinction can be made between the materials needs for syngas-based fuels and hydrogen. For syngas combustion, consideration must be given to the possibility that the combustion products may contain levels of contaminants (from the coal) capable of providing accelerated surface degradation through deposition, erosion, or corrosion. The increased levels of water vapor from syngas also are thought to be capable of modifying the characteristics of the normally-protective oxide films formed on alloys and coatings. For hydrogen fuel scenarios, the additional processing steps experienced by the fuel make it likely that the only source of such contaminants will be the combustion air (if used), so that the major environmental concerns will be high-temperature oxidation, particularly water vapor-accelerated oxidation from the higher levels of water vapor-accelerated oxidation from the higher levels of water vapor in the combustion gas, and possibly hydrogen embrittlement from steam. In addition, the combustion temperatures for hydrogen-based fuels are expected to be higher than for syngas, so that materials options that maximize temperature capability, and component designs that maximize cooling will be paramount.

\subsection{NEEDS RESULTING FROM THE PURSUIT OF HIGHER FIRING TEMPERATURES}

The differences in CV and combustion characteristics among natural gas, syngas, and hydrogen have significant implications for the ability to maintain power output, emissions levels, and component cooling. As indicated earlier, there is concern that these issues, as they affect gas temperatures and flow rates, will require changes or compromises in the detailed design of the turbine in order to provide sufficient control of the temperatures of critical components to ensure their reliability. There is little margin for increasing the operating temperature of the superalloys available for use in large turbines, so that it appears essential that the temperatures expected to be experienced by critical hot gas path components be carefully defined for the range of combustion conditions likely in any given turbine operating scenario. This requirement highlights the 
need for measurement and/or modeling developments to provide confidence in setting operating parameters and limits in the context of materials performance.

There are several pressing issues. One is the design of combustor systems capable of coping with the flame characteristics of the range of fuels of interest. The need to control the combustion process to avoid flame detachment from the burner nozzles to prevent overheating, and of avoiding flashback while maintaining the desired low levels of $\mathrm{NO}_{\mathrm{x}}$, ideally requires combustion zones of specific dimensions and/or shape for each fuel. This situation makes the concept of dual- or multi-fuel capability difficult to achieve in a single combustor design. Combustor liner materials typically are highly-cooled alloys with, in some cases, little margin for temperature increase, so that materials that require less cooling would provide improved operating flexibility, and are a continuing need.

For the airfoils, the primary need is to reduce the initial costs and to simplify the manufacturing procedures for SC components. It is considered likely that the alloys that will be preferred will have improved castability and production yield, which are likely to be achieved at the expense of limitations in high-temperature capabilities. Some progress already has been made in this regard. Nevertheless, it appears that the compromises necessary to achieve an acceptable cost reduction in SC components available for land-based turbines will lead to alloys that have maximum metal temperature capabilities that are at best similar to those of the current $2^{\text {nd }}$ generation SC alloys. Their actual maximum use temperatures will be limited by engine size, loading per stage, and duty cycle, and by innovations in design. Thus, the available mechanical property data for, for instance, alloy CMSX-4 should provide a good guide for suggesting the maximum permissible metal temperature for superalloys for land-based turbines and, since this will be significantly lower than the rotor inlet temperatures commensurate with the goals listed in Table 6, there will be a need to carefully control turbine operation to ensure that these temperatures are not exceeded.

In general, since it appears that the development of Ni-based superalloys for land-based turbines has reached the point where further gains in temperature capability are likely to be small, and since on the basis of present evidence no successor material (such as ceramics or refractory-based alloys) will emerge in the near future, further increases in firing temperatures will require an overall approach combining optimization of alloy compositions and cooling technologies (including thin-walled castings and TBCs). This is particularly necessary where combustion temperatures may be 
appreciably higher than in current experience (as appears to be the case for hydrogenoxygen combustion). In particular, since coatings likely will comprise a significant fraction of the thickness of the vane/blade wall, greater attention will need to be devoted to improving the compatibility of alloys and coatings, as loss of useful wall section through corrosion or interaction between coating and superalloy will be very detrimental.

For rotors and discs, materials currently in use in gas turbines burning natural gas are operated at the limits of their high-temperature strength, and will be inadequate should higher temperatures be necessary for improved efficiency with syngas/hydrogen firing. In this case, greater use of nickel-chromium alloys will be inevitable and, depending on the detailed characteristics of the engine design, efforts to further improve the manufacturing processes and reduce costs will be necessary. In addition, there is a requirement for long-term data on mechanical properties (thermo-mechanical fatigue in particular) to provide a basis for increased component lifetime and lifetime modeling. Improved computational modeling techniques for life prediction of critical components are required, and will contribute to the overall aim of enhanced component durability.

Overall, there are materials available or under development that are capable of the performance and durability for the nominal conditions of syngas applications, but only provided that the relevant components are cooled so that they do not exceed prescribed temperatures.

\subsection{EVOLVING NEEDS FROM CONSIDERATION OF HYDROGEN AS GAS TURBINE FUEL}

The scenarios for the use of hydrogen in IGCC/GTCC applications were still being evolved as this report was prepared, so that any conclusions concerning specific materials needs probably are premature. Nevertheless, the following comments are offered. The implications for materials selection and use from scenarios for augmenting syngas with hydrogen, and the issues from using air-oxygen mixtures for combustion are probably very similar to those discussed above for syngas. The major differences arise for the case where hydrogen and oxygen are the sole/major reactants, in cycles aimed at minimizing emissions. Such cycles typically involve gas temperatures at or above the extreme upper limit of those considered (and certainly above the range for which there is experience) in conventionally-fueled land-based turbines. Because testing in such environments will be difficult and expensive, modeling approaches that are capable of 
generating data on the local temperatures and heat transfer conditions experienced by the hot gas-path components that are associated with the various combustion scenarios are probably the only means of providing vital guidance for materials selection and cooling requirements, and will be extremely valuable. Since increases in firing temperature probably cannot be accommodated by the incremental improvements in current materials discussed above, new approaches to cooling of critical components probably will be needed, or a commitment made to combinations of radical design and materials applications, and to pioneering of their insertion into critical areas.

The additional processing required to convert syngas to hydrogen and to extract oxygen from air is considered to effectively remove all impurities typically implicated in hot gas path corrosion, so that the main environmental concerns are with the corrosive effects of high-temperature and high-pressure steam (including hydrogen embrittlement). This also is an area where data are scarce, so that a commitment to some relatively fundamental materials compatibility research will be necessary.

\subsection{NEEDS RESULTING FROM CONCERNS ABOUT FUEL PURITY}

An additional important difference compared to prior experience with natural gasfired GTCC practice is the range and level of potential impurities possible in syngas, and the implications for alloy/coating durability. Even though it is expected that the fuel supplied to the turbine will be within current fuel specifications, there is a need for better understanding and quantification of the potential threat to component durability from (1) the higher water vapor levels, and (2) the different impurities possible in gasifier streams, which can vary significantly among gasifier types and gas clean-up configurations. A definitive evaluation of the actual gas compositions delivered to the turbine, together with understanding of the disposition of the species resulting from combustion, is considered essential for assessing potential implications for the range of gasification processes, clean-up options, and turbine designs of interest.

Depending on the likelihood of the presence in the combustion gas of sufficient quantities of species that have the potential to contribute to problems of D-E-C, coatings with increased resistance to sulfur-related oxidation-sulfidation or hot corrosion may be needed. These coatings will require significantly different compositions than current coatings, which have been optimized for resistance to high-temperature (sulfur-free) oxidation. An issue here is the need to ensure that the mechanical properties of the 
coatings do not degrade the resistance of the airfoils to, for instance, thermalmechanical fatigue. In addition, since these turbines are expected to operate at very high temperatures for long times, it is necessary to ensure compatibility between coatings and superalloy substrates, especially in terms of reducing the effects of interdiffusion on the stability of the alloy microstructure, and the life of the coating. A well-known issue is that the properties of sulfidation resistance, oxidation resistance, and compatibility with SC alloy compositions (in terms of chemical interactions) usually are not readily combined in a single coating composition. Thus, there may be opportunities for developing hybrid coating designs capable of combining some of these functions.

There may be potential for further development of polycrystalline, DS materials, since there is probably more scope for increasing their chromium content than for SC compositions. It is likely that a key requirement of components for which DS alloys are candidates will be for alloys with greater corrosion resistance, while maintaining hightemperature strength, and this will be a challenging task. Also, as was the case for rotors and discs, long-term data on both creep and fatigue properties, and improvements in computational modeling methods, will contribute to better durability of these critical components.

\subsection{OVERALL SUMMARY OF MATERIALS NEEDS}

The materials issues resulting from the need for advanced gas turbines to operate with fuels other than clean, natural gas are summarized in Table 7, which attempts to provide a simple ranking of the level of effort necessary to provide the needed materials. In the Table, the level of effort required has been given a subjective numerical rating from 1 to 3 , where ' 1 ' suggests that considerable research and development will be needed, while a ranking of ' 3 ' indicates that most of the capability required is already available. Distinction is made between the materials needs for syngas and hydrogen, on the assumption that the combustion of hydrogen will involve higher temperatures and certainly higher levels of water vapor.

Finally, there exists a major need to demonstrate that available materials can be made into actual components that work as intended, and to obtain property data for design purposes and service life prediction. While demonstration of the workability of a syngas- or hydrogen-fired advanced gas turbine is an expensive undertaking, even at 
component-demonstration level, it represents a necessary milestone that must be reached in order for the utility industry to accept this technology. It is therefore recommended that a demonstration phase (at least for materials and key components) is indicated as a common culmination point for all materials and components development programs.

Table 7. Ranking of overall materials needs

\begin{tabular}{|c|c|c|c|c|}
\hline \multirow{2}{*}{\multicolumn{2}{|c|}{ Component }} & \multicolumn{2}{|c|}{ Rating } & \multirow{2}{*}{ Major issues } \\
\hline & & \multirow{2}{*}{$\begin{array}{c}\text { Syngas } \\
2\end{array}$} & \multirow{2}{*}{$\frac{\mathrm{H} 2}{1}$} & \\
\hline Combustors & Materials & & & Cooling; TBCs; lifetime \\
\hline & Manufacturing & 2 & 1 & Design for multifuel use \\
\hline \multirow[t]{2}{*}{ Vanes/blades } & Materials & 3 & 1 & $\begin{array}{l}\text { Higher-T capability; better corrosion } \\
\text { resistance; lower cost }\end{array}$ \\
\hline & Manufacturing & 2 & 1 & Improved yield; lower cost \\
\hline \multirow[t]{2}{*}{ Bond coatings } & Materials & 1 & 1 & Durability/compatibility with superalloy \\
\hline & Manufacturing & 2 & 1 & Cost; process control \\
\hline $\begin{array}{l}\text { Ceramic } \\
\text { thermal barrier }\end{array}$ & Materials & 1 & 1 & $\begin{array}{l}\text { Reduced thermal conductivity; longer } \\
\text { lifetime; predictability }\end{array}$ \\
\hline layers & Manufacturing & 2 & 1 & Cost; reproducibiity \\
\hline \multirow[t]{2}{*}{ Rotors/discs } & Materials & 3 & 2 & $\begin{array}{l}\text { Large Ni-base forgings; design data; } \\
\text { weldability }\end{array}$ \\
\hline & Manufacturing & 1 & 1 & Melting, forging, fabrication (welding?) \\
\hline
\end{tabular}




\section{CONCLUSIONS}

- The stated performance goals for turbines intended for operation on syngas and hydrogen fuels will require firing temperatures at least as high as those achieved by state-of-the-art turbines designed for natural gas.

- For syngas service, there are complicating factors due to differences in CV and combustion characteristics compared to natural gas, and these have significant implications for the ability to maintain power output, emissions levels, and component cooling. The potential threat of environmental degradation from fuelderived impurities in syngas introduces further differences in materials performance requirements compared to natural gas firing.

- A consequence of the use of hydrogen fuel will be the need for higher firing temperatures, together with the threat of high-temperature oxidation and hydrogen embrittlement in steam under conditions for which there is little prior experience.

- For components, such as blades and vanes, exposed to the highest temperatures in large gas turbines for power generation applications, several SC alloys are available with a well-established record of performance (in natural gas service).

- Recent advances in understanding the factors controlling defect formation during the production of SC castings have resulted in alloys optimized for tolerance of defects and simplified post-casting heat treatments, and consequently lower costs.

- Improvements in DS alloys (with columnar grain structures) have provided some options for enhanced performance for components operating at somewhat lower temperatures.

- Developments in coating systems (bond coatings and thermal barriers) have contributed to component durability in natural gas service, although reliability needs improvement. However, such coatings were developed for resistance to hightemperature oxidation, and may not provide sufficient protection against potential sulfur-related corrosion scenarios from impurities in syngas.

- Some progress has been claimed in the development of ceramic composites for combustor liners.

- Ni-base alloys have been developed that are suitable for replacing ferritic steels for large-diameter discs for higher-temperature applications in high-pressure turbines, but forging processes are problematical. 
- Because the proposed applications will involve the operation of high-temperature materials near their performance limits, it will be critical to possess accurate knowledge of the conditions actually experienced in service. Acquisition of such knowledge probably will require a combination of analytical and sensing techniques.

- The use of analytical modeling appears to be essential for the generation of information to guide materials selection and cooling requirements/component design for the hydrogen combustion scenarios, for which materials compatibility information is sparse, and in which testing will be difficult.

- Long-term data on the creep fatigue and stress relaxation behavior of critical materials will be required to provide an improved basis for design of hot gas path parts and the related materials selection. 


\section{ACKNOWLEDGMENTS}

This work was funded by the Office of Coal and Power R\&D, Office of Fossil Energy, U.S. Department of Energy, under contract DE-AC05-00OR22725 with UT-Battelle, LLC, with technical management by the National Energy Technology Laboratory (NETL), Morgantown, West Virginia. Discussions with the NETL staff, especially with Richard Dennis and George Richards, are gratefully acknowledged. We would also like to acknowledge helpful comments by staff members of General Electric, Greenville, South Carolina; Siemens Power Generation, Incorporated, Orlando, Florida; Alstom Power, Baden, Switzerland (especially Peter Holmes); and from Fred Starr (currently at the European Joint Research Centre, Petten, The Netherlands), and by colleagues Bruce Pint, Peter Tortorelli, and Dane Wilson at ORNL. We are grateful to Gordon McColvin, of Siemens for the provision of figures. 



\section{REFERENCES}

1. P. D. Holmes, Gas Turbine Development Strategy, www.came-gt.com.

2. W. P. Parks, Jr., P. Hoffman, M. A. Karnitz, and I. G. Wright," The Advanced Turbine Systems Program in the U.S.A.," pp. 1789-1805 in Materials for Advanced Power Engineering 1998, J. Lecomte-Beckers, F. Schubert, and P. J. Ennis, Eds., Forschungszentrum Julich (1998).

3. S. Nagamatsu, K. Mizuhara, Y. Matsuta, A. Iwanaga, and S. Ishiwata, "Current Status of Industrial and Automotive Ceramic Gas Turbine R\&D in Japan," Paper No. 91-GT-101, presented at the ASME Intl. Gas Turbine \& Aeroengine Congress and Exposition, Orlando, Florida (1991).

4. High-Temperature Materials 21 Project, Conducted by NIMS, Japan, 1999 to 2008.

5. Programs under the European Cooperation in the Field of Scientific and Technical Research (COST) framework; COST 501 Focused on Advanced Materials for Power Engineering Components for High-Efficiency, LowEmissions Systems. COST Website: http://cost.cordis.lu.

6. Figure from Siemens Power Generation, www.powergeneration.siemens.com.

7. J. Natarajan, S. Natarajan, S. Nandula, T. Lieuwen, and J. Seitzman, "Lamina Flame Speeds of Synthetic Coal Gas Mixtures," ASME paper No. GT-2005-68917, presented at the ASME Turbo Expo 2005: Power for Land, Sea, and Air, Reno-Tahoe, Nevada (2005).

8. Q. Zhang, D.R. Noble, and T. Lieuwen, "Blowout Measurements in a Syngas-Fired Turbine Combustor," presented at the $22^{\text {nd }}$ Ann. Intl. Pittsburgh Coal Conference, Pittsburgh, Pennsylvania (2005).

9. www.EngineeringToolbox.com.

10. GREET Transportation Fuel Cycle Analysis Model (v.1.7 beta), ANL (2006); www.transportation.anl.gov/software/GREET/index.html.

11. H.I.H. Saravanamuttoo, C.F.C. Rogers, and H. Cohen, Gas Turbine Theory, 5th Edtn., FT-Prentice Hall (2001).

12. See, for instance, "Specification for Fuel Gases for Combustion in HeavyDuty Gas Turbines," General Electric Specification GEI 41040G, revised January 2002.

13. See, for instance, M. Valenti, "Reaching for 60 Percent," Mechanical Engineering, 124 (4), 35-39 (2002). 
14. F. C. Holden, H. J. Cialone, M. P. Landow, I. G. Wright, and C. M. Jackson, Combustion Turbine Materials Problems, EPRI AP-4475 (RP 2382-2), March 1986.

15. T. B. Gibbons, pp.123-135 in Processing and Design Issues in HighTemperature Materials, N. S. Stoloff and R. H. Jones, Eds., TMS, Warrendale, PA (1996).

16. G. L. Erickson and K. Harris, "DS and SX Superalloys for Industrial Gas Turbines," pp. 1055-1074 in Materials for Advanced Power Engineering 1994, D. Coutsouradis, J. H. Davidson, J. Ewald, P. Greenwood, T. Khan, M. Malik, D. B. Meadowcroft, V. Regis, R. B. Scarlin, F. Schubert, and D. V. Thornton, Eds., Kluwer Academic Publishers (1994).

17. Y. Koizumi, et al., Superalloys 2004, pp. 35-43, K. A. Green, T. M. Pollock, H. Harada, T. E. Howson, R. C. Reed, J. J. Schirra and W. S. Walston, Eds. TMS, Warrendale, PA, 2004.

18. K. Harris and J. B. Wahl, ibid. pp. 45-52.

19. R. Hashizume et al., ibid. pp 53-62.

20. R. Hashizume, A. Yoshinari, T. Kiyono, Y. Murata, and M. Morinaga, "Development of Ni-Based Single Crystal Superalloys for Power-Generation Gas Turbine Blades," pp. 273-286 in Materials for Advanced Power Engineering 2006, J. Lecomte-Beckers, M. Carton, F. Schubert, and P. J. Ennis, Eds., Schriften des Forschungszentrums Jülich Reihe Energietechnik/Energy Technology, $\underline{53}$, part 1 (2006).

21. A. Sato, A-C Yeh, T. Kobayashi, T. Yokokawa, H. Harada, T. Murakumo, and J. Zhang, "A $5^{\text {th }}$ Generation Ni-based Single Crystal Superalloy with Superior Elevated Temperature Properties," ibid., pp. 287-298.

22. M. Lamm, A. Volek, O. Luesebrink, and R. F. Singer, "Influence of Solidification Conditions on Homogenization Heat Treatment and Mechanical Properties in Single Crystal Nickel-Base Superalloys," ibid., pp. 334-344.

23. See, for instance, Proc. Workshop on Materials and Practices to Improve Resistance to Fuel-Derived Environmental Damage in Land- and Sea-Based Turbines, EPRI report No. 1009173, Oct. 2003.

24. R. Burgel et al., Superalloys 2004, pp. 25-34. K.A. Green, T. M. Pollock, H. Harada, T. E. Howson, R. C. Reed, J. J. Schirra and W. S. Walston, Eds. TMS. Warrendale, PA, 2004.

25. M. Sato et al, $2^{\text {nd }}$ Int. Symp. On High Temperature Materials, NIMS, Japan, pp. 28-29, 2001. 
26. W. S. Walston, Superalloys 2004, pp 579-588, K. A. Green, T. M. Pollock, H. Harada, T. E. Howson, R. C. Reed, J. J. Schirra, and W. S. Walston, Eds, TMS Warrendale, PA, 2004.

27. J. A. Haynes, M. J. Lance, B. A. Pint, and I. G. Wright, "Characterization of Commercial EB-PVD TBC Systems with CVD(Ni, Pt) Al Bond Coatings," Surface Coatings Technology, 146-147, 140-146 (2001).

28. See, for instance: A. G. Evans, J. W. Hutchinson, and M. Y. He, Acta Met., 47, 1513-1522 (1999).

29. P. Deb, D. H. Boone, and T. F. Manley, J. Vac. Sci. Technol. A., $\underline{5}$ (6), 3366 (1987).

30. See, for instance: M. Gell, K. Vaidyanathan, B. Barber, J. Cheng, and E. Jordan, Metal. Mater. Trans., 30A, 427-435 (1999).

31. J. G. Smeggil, A. W. Funkenbusch, and N. S. Bornstein, Met. Trans., $\underline{17 A}$, 923 (1986).

32. J. L. Smialek and B. K. Tubbs, Met. Trans., 26A, 427-435 (1995).

33. B. A. Pint, I. G. Wright, W. Y. Lee, Y. Zhang, K. Prüssner, and K. B. Alexander, Mat. Sci \& Eng., A245, 201-211 (1998).

34. P. Morell, D. S. Rickerby, pp. $20-21$ to $20-29$ in Proc. AGARD-R-823 (1998).

35. C. G. Levy et al., Coatings for Advanced Gas Turbines, Summary of Research Needs and Proposed Actions, prepared for DOE, FETC.

36. M. P. Borom, C. A. Johnson, and A. L. Peluso, "Role of Environmental Deposits in Spallation of Thermal Barrier Coatings on Aero Engine and Land-Based Gas Turbine Hardware," Paper No. 96-GT-285, presented at the ASME Turbo Expo ‘96, June 10-13, 1996, Birmingham, England.

37. M. F. Trubelja, D. M. Nissley, N. S. Bornstein, and J.T.D. Marcin, "Pratt \& Whitney Thermal Barrier Coating Development," in Proceedings, Advanced Turbine Systems Annual Program Review Meeting, DOE/FETC-98/1057, DE98002004, CONF-971053 (Report No. 5.9) (1997).

38. See, for instance, M. J. Maloney U.S. Patent No. 6,284,323, 2001.

39. J. Kimmel, J. Price, K. L. More, P. F. Tortorelli, E. Sun, and G. Linsey, "The Evaluation of CFCC Liners after Field Testing in a Gas Turbine-IV," paper No. GT2003-38920 in Proc. ASME Turbo Expo 2003: Power for Land, Sea and Air, Atlanta, Georgia, USA (2003).

40. A. Szweda, S. Butner, J. Ruffoni, C. Bacalski, J. Layne, J. Morrison, G. Merrill, M. van Roode, A. Fahme, D. Leroux, and N. Miriyala, "Development and Evaluation of Hybrid Oxide/Oxide Ceramic Matrix 
Composite Combustor Liners," paper No. GT2005-68496 in Proc. ASME Turbo Expo 2005: Power for Land, Sea and Air, Reno/Tahoe, Nevada, USA (2005).

41. J. A. DiCarlo and M. van Roode, "Ceramic Composite Development for Gas Turbine Engine Hot Section Components," paper No. GT2006-90151 in Proc. ASME Turbo Expo 2006: Power for Land, Sea and Air, Barcelona, Spain (2006).

42. F. Carchedi, pp. 3-23 in Engineering Issues in Turbine Machinery Power Plant and Renewables 2003, A. Strang, R.D. Conroy, W.M. Banks, M. Blackler, J. Leggett, G.M. McColvin, S. Simpson, M. Smith, F. Starr and R. W. Vanstone, Eds, IOM, London 2003.

43. P. W. Schilke, J. J. Pepe, and R. C. Schwant, "Alloy 706 Metallurgy and Turbine Wheel Application," pp. 1-12, in Superalloys 718, 625, 706, and Various Derivatives, E. A. Loria, Ed., TMS Publications (1994).

44. R. C. Schwant, S. V. Thamboo, A. F. Anderson, C. B. Adasczik, B. J. Bond, L. A. Jackman, and J. F. Uginet, "Large 718 Forgings for Land Based Turbines," pp. 141-152 in Superalloys 718, 625, 706, and Various Derivatives, E. A. Loria, Ed., TMS Publications (1997).

45. P. W. Schilke, and R. C. Schwant, "Alloy 706 Use, Process Optimization, and Future Directions for GE Gas Turbine Rotor Materials," pp. 25-34 in Superalloys 718, 625, 706, and Various Derivatives, E. A. Loria, Ed., TMS Publications (2001).

46. R. C. Schwant, S. V. Thamboo, L. Yang, and M. Morra, "Extending the Size of Alloy 718 Rotating Components," pp. 15-24 in Superalloys 718, 625, 706, and Various Derivatives, E. A. Loria, Ed., TMS Publications (2005).

47. See for instance, Casting Simulation Solutions: PROCAST/QUICKCAST, ES1 North America, Bloomfield Hills, Michigan (2007).

48. D. A. Woodford, "Stress Relaxation Testing," pp. 398-404 in Mechanical Testing and Evaluation, Vol. 8, ASM Handbook (2000).

49. N. Saunders, Z. Guo, X. Li, A. P. Miodownik, and J-Ph. Schille, "Modeling the Materials Properties and Behavior of Ni-Based Superalloys," Superalloys 2004, pp. 849-858, K. A. Green, T. M. Pollock, H. Harada, T. G. Howson, R. C. Reed, J. J. Schirra and W. S. Walston, Eds., TMS Warrendale, PA (2004).

50. A. M. Othman, B. F. Dyson, D. R. Hayhurst, and J. Lin, "Continuum Damage Mechanics Modeling of Circumferentially-Notched Tension Bars Undergoing Tertiary Creep with Physically-Based Constitutive-Equations," Acta Metall. Mater., 42, 597-611 (1994).

51. J. Yang et al., ASME J. Pressure Vessel Technology, 126, 369-375 (2004). 
52. H. Basoalto, S. K. Sondhi, B. F. Dyson, and M.McLean, "A Generic Microstructure-Explicit Model of Creep in Ni-Base Superalloys," pp. 897-906 in Superalloys 2004, K. A. Green, T. M. Pollock, H. Harada, T. G. Howson, R. C. Reed, J. J. Schirra and W. S. Walston, Eds., TMS Warrendale, PA (2004).

53. B. F. Dyson, ASME, J. Pressure Vessel Technology, 122, 2000, pp. 281-296.

54. "Enabling Turbine Technologies for High-Hydrogen Fuels," U.S. Department of Energy Solicitation No. DE-PS26-05NT42380, issued March 31, 2005.

55. K. Onal, M. C. Maris-Sida, G. H. Meier, and F. S. Pettit, "The Effects of Water Vapor on the Oxidation of Ni-Base Superalloys and Coatings at Temperatures from 700 to $1100^{\circ} \mathrm{C}$," pp. 607-615 in Superalloys 2004, K. A. Green, T. M. Pollock, H. Harada, T. G. Howson, R. C. Reed, J. J. Schirra and W. S. Walston, Eds., TMS Warrendale, PA (2004).

56. B. A. Pint, J. A. Haynes, Y. Zhang, K. L. More and I. G. Wright, "The Effect of Water Vapor on the Oxidation Behavior of Ni-Pt-Al Coatings and Alloys," Surface and Coatings Technology, 201, 3852-3856 (2006).

57. E. J. Opila, "Volatility of Common Protective Oxides in High-Temperature Water Vapor: Current Understanding and Unanswered Questions," Materials Science Forum, 461-464, 765-773 (2004).

58. D. Bohn, Modern Power Systems, September 2006, pp. 25-27.

59. "Enabling Turbine Technologies for Hydrogen Fuels," DOE-Fossil Energy Techline, Sept. 8, 2005.

60. See, for instance, R. Anderson, H. Brandt, S. Doyle, K. Pronske F. Viteri, "Power Generation with 100\% Carbon Capture and Sequestration," Presented at the 2nd Annual Conference on Carbon Sequestration, Alexandria, VA, May 5-8, 2003.

61. C. Mitsugi, A. Harumi, and F. Kenzo, "Japanese Hydrogen Program," Int'l. J. of Hydrogen Energy, 23 (3), 159-165 (1998).

62. R. L. Bannister, R. A. Newby, and W. C. Yang, "Development of a HydrogenFueled Combustion Turbine Cycle for Power Generation," J. Eng. for Gas Turbines and Power, 120, 276-283 (1998).

63. R. Viswananthan, J. F. Henry, J. Tanzosh, G. Stanko, J. P. Shingledecker, B. Vitalis, and R. Purgert, "U.S. Program on Materials Technology for UltraSupercritical Coal Power Plants," Journal of Materials Engineering and Performance, 14 (3), 281-292 (2005).

64. P.J. Maziasz, I. G. Wright, and V. Viswanathan, "Advanced Materials for USC Steam Turbines," presented at the Clean Coal Conference, Clearwater, FL (2006). 
65. Granta MI Software, Granta Design, Ltd., Cambridge, England. 
ORNL/TM-2009/137

\section{INTERNAL DISTRIBUTION}

1. S. J. Pawel

2. B. A. Pint

3. F. C. Stooksbury

4. P. F. Tortorelli

5. D. F. Wilson
6-25. I. G. Wright

26. S. J. Zinkle

27. Central Research Library

28. ORNL Laboratory Records-RC

\section{EXTERNAL DISTRIBUTION}

29. C. T. Alsup, DOE National Energy Technology Laboratory, 3610 Collins Ferry Road, P.O. Box 880, Morgantown, WV 26507-0880

30. M. A. Alvin, DOE National Energy Technology Laboratory, 626 Cochrans Mill Road, P.O. Box 10940, Pittsburgh, PA 15236-0940

31. B. Bordenet, Alstom (Switzerland) Ltd., Dept. TGTM, Brown Boveri Strasse 7, 5401 Baden, Switzerland

32. R.A. Dennis, DOE National Energy Technology Laboratory, 3610 Collins Ferry Road, P.O. Box 880, Morgantown, WV 26507-0880

33. R.B. Dooley, Structural Integrity Associates, Inc., 2616 Chelsea Drive, Charlotte, NC 28209

34. D. Gandy, EPRI, 1300 West W.T. Harris Blvd, Charlotte, NC 28262

36-41. T.B. Gibbons, Consultant, 5005 Nicholas Creek Circle, Wilmington, NC 28409

42. D. Helmick, General Electric Energy, Materials and Processes Engineering, PO Box 648, Greenville, SC 29602

43. A. James, Siemens Power Generation Inc., Superalloy Technology (USA), 4400 Alafaya Trail, MC Q3-031, Orlando, FL 32826-2399

44. A. A. Kulkani, Siemens Power Generation Inc., Materials Engineering, 4400 Alafaya Trail, MC Q3-031, Orlando, FL 32826-2399 
45. G.M. McColvin, Siemens Industrial Turbomachinery, Ruston House, P.O. Box 1, Waterside South, Lincoln LN5 7FD, England

46. A. Manivannan, DOE National Energy Technology Laboratory, 3610 Collins Ferry Road, P.O. Box 880, Morgantown, WV 26507-0880

47. P. A. Rawls, DOE National Energy Technology Laboratory (NETL-PGH), Gasification and Fuels Division, P.O. Box 10940, 626 Cochrans Mill Road, Pittsburgh, PA 15236-0940

48. Robert R. Romanosky, Jr., DOE National Energy Technology Laboratory, (NETL-MGN), Office of Coal and Power Research and Development, P.O. Box 880, 3610 Collins Ferry Road, Morgantown, WV 26507-0880

49. John Shingledecker, Senior Project Manager, Fossil Materials \& Repair Program (P87), EPRI, 1300 West W. T. Harris Blvd., Charlotte, NC 28262

50. N. J. Simms, Cranfield University, School of Industrial and Manufacturing Science, Power Generation Technology Centre, Cranfield MK43 0AL, Beds., England

51. F. Starr, Visiting Scientist, JRC-European Commission, P.O. Box 2, 1755 ZG Petten, The Netherlands

52. J. Stringer, Izambard, 221 Hudson Street, Redwood City, CA 94062-1921

53. R. Viswanathan, EPRI, 3412 Hillview Ave., Palo Alto, CA 94303

54. R. A. Wenglarz, SCIES, 386-2 College Avenue, Clemson, SC 29634 